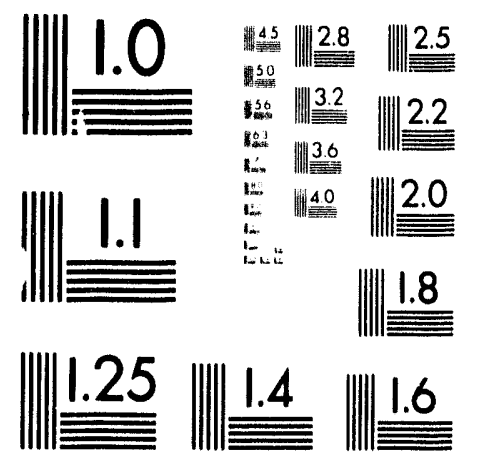



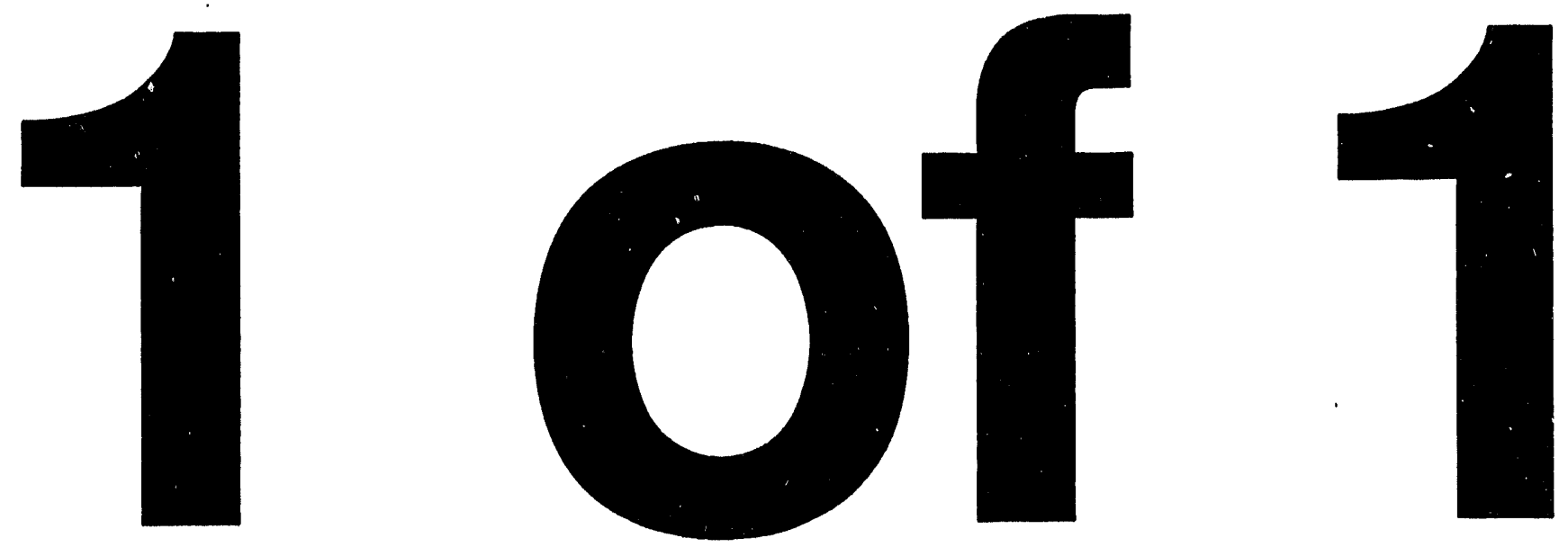


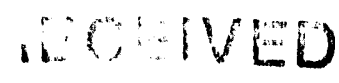

NOV 081993

ANL/APS/IN/VIB-93/8

August 1993

\title{
OSTI
}

\section{RESPONSE OF THE RF-EXTRACTION-WING BALCONY AND FLOOR, AND THE STORAGE RING TO FORCED AND AMBIENT VIBRATION EXCITATION AND COUPLING TO TUNNEL/BASEMAT}

\author{
by
}

\author{
J. A. Jendrzejczyk, M. W. Wambsganss, R. K. Smith, and P. Rosas-Velez \\ Argonne National Laboratory
}

\section{INTRODUCTION}

To ensure successful operation of the APS, vibration of the storage ring quadrupole magnets must be limited to very low levels for frequencies $>10 \mathrm{~Hz}$, see Ref. 1. There will be many sources of vibration, such as pumps, fans, compressors, generators, and other rotating and reciprocating machinery when the APS is operational. In general, such vibration sources are isolated from the structural components and base foundations by vibration dampers and isolators. Pumps are typically mounted on seismic isolators, which are massive bases with response frequencies of $<10 \mathrm{~Hz}$, and fans are mounted with elastic-type isolators to minimize vibration coupling. Vibration coupling between various structural components of a building, e.g., balconies and floors, and the storage ring basemat is minimized by soft expansion/isolation joints. Other techniques, which utilize distance, can also be used to effectively reduce vibration, e.g., the placement of the utility building.

The attenuation "efficiency" of these expansion/isolation joints is a very important factor in predicting the response of the storage ring basemat to the various excitation sources. Several 75 -hp pumps are located on the balcony of the $\mathrm{RF}$ extraction wing, which is close to the storage ring basemat. The pumps per se may prove to be a vibration excitation source of concern. Additional pumps will be placed in the RF extraction building and could add to the vibration levels. If the dynamic unbalance force of the pump motor, and the efficiency of the associated expansion joints were known, we could predict the response of the storage ring basemat. This information would also be useful in determining the placement of additional pumps.

This report discusses vibration tests and measurements that were performed on July 28,1993 , in the RF extraction building. The purpose of the investigation was to study the efficiency of two specific expansion joints: (1) the joint that 
separates a structural column pad from the extraction wing floor, and (2) the joint that separates the extraction wing floor from the roof of the storage ring tunnel. A small electrodynamic exciter, with a maximum RMS force output of $\approx 0.5 \mathrm{lb}$ at the frequencies of interest, was used. Dynamic response to ambient vibration was also measured, to compare the response to previous levels and spectral content.

\section{TEST OBJECTIVES}

The test objectives were to (a) measure the vibration coupling between the RFextraction-wing floor and the storage ring basemat, and between the RF-extractionwing balcony and the storage ring basemat, (b) measure, at various locations, the vibration due to ambient site vibration, and (c) determine, from a vibration standpoint, optimum positions for the placement of additional pumps.

\section{TECHNICAL APPROACH}

To measure vibration coupling between the various floor slabs and structures, a known source of vibration is required. A small electrodynamic exciter, capable of producing an RMS output force of $\approx 0.5 \mathrm{lb}$ with a frequency range of $20-100 \mathrm{~Hz}$, provided vertical excitation to the RF-extraction-wing floor and balcony at the locations shown in Fig. 1. The exciter amplitude and frequency was controlled by a Zonic fast Fourier transform (FFT) analyzer, which provided a constant-amplitude force and varied frequency in increments of $1 \mathrm{~Hz}$. Attenuation of vipration frequencies of 29-30 and 58-60 Hz was of specific interest because these frequencies correspond to pump electric motor speeds of $1740-1800$ and $3480-3600 \mathrm{rpm}$, respectively. When operational, $75-\mathrm{hp}$ pumps on the balcony will operate at a rotational speed of $3550 \mathrm{rpm}$.

To measure the vibration response of the various components, seismometers (sensitive accelerometers) were mounted at Locations 1-7 indicated in Fig. 1. A more detailed illustration showing the locations of the pumps and principal components on the balcony, along with the position of the exciter and instrumentation, is given in Fig. 2. The geometries were oriented to measure vertical acceleration, because the limit of the vibration level of the vertical component of the storage ring quadrupole magnet is the most critical $(0.35$ that of the horizontal), see Ref. 1. Because ambient vibration excitation is present at all times, including when the exciter is in operation, the measured response will include contributions from both sources. To achieve the most accurate measurements, it is desirable to minimize the ambient response and maximize the exciter response. However, to avoid mechanical damage to the structures, and to

avoid potential nonlinear responses, the excitation force should be limited to 
realistic values, that is, those anticipated during normal APS operation. While the ambient excitation is broadband, the response to the exciter will be at specific, selected frequencies. Digital filtering techniques are used to effectively minimize the effect of ambient excitation.

The procedure for forced excitation testing is as follows. The frequency is set to the lower limit, typically $20 \mathrm{~Hz}$, and the exciter is activated, generating a $20-\mathrm{Hz}$ vertical force into the floor. The acceleration response at each of the seven locations is averaged in a computer for $\approx 24 \mathrm{~s}$, converted to displacement by double integration, and stored in a specific file, corresponding to the excitation frequency. The exciter is turned off, the frequency is shifted upward by $1 \mathrm{~Hz}$ (new excitation frequency is now $21 \mathrm{~Hz}$ ), the exciter is reactivated, and data acquisition resumes. This cycle repeats until the upper frequency limit is reached. From the measured values, system response and attenuation, as a function of frequency, can be calculated. A computer program was written for the Zonic FFT to automate the described procedure.

The ambient vibration response is measured with the seismometers in the same location as in the forced-excitation tests. The acceleration signals are converted to displacement by double integration; however, digital filtering techniques are not used; the measured displacement bandwidth is $1-100 \mathrm{~Hz}$. Power spectral density spectra are also recorded to compare spectral content with previously measured data.

\section{TEST DESCRIPTION}

The test conditions were as follows.

Condition 1 - The exciter was placed on the floor of the RF extraction building in the position, shown in Fig. 1, to simulate a vibration source, such as a pump electric motor, mounted to the floor. Frequency was varied from 20 to $100 \mathrm{~Hz}$ in $1-\mathrm{Hz}$ increments. Vibration amplitudes were measured simultaneously at the seven locations shown in Fig. 1. Measured RMS displacements from the various measurement location groups are shown in Figs. 3-5. Attenuation factors, calculated from the measurement data, are shown in Figs. 6-8 as a function of frequency. A power function relationship was curve-fit to the data in an attempt to quantify the attenuation.

Condition 2 - The exciter was placed on the concrete section of the balcony of the RF extraction building, as shown in Figs. 1-2, to simulate the operation of the four 75-hp pumps (WPW-904-907). Frequency was varied from 20 to $80 \mathrm{~Hz}$ in $1-\mathrm{Hz}$ increments. Vibration amplitudes were measured simultaneously at the same 
seven locations as in Condition 1. Measured RMS displacements from the various measurement location groups are shown in Figs. 9-11. Attenuation factors, calculated from the measurement data, are shown in Figs. 12-14 as a function of frequency.

Condition 3 - The exciter was located in the same position as in Condition 2. Frequency was varied from 3 to $12.5 \mathrm{~Hz}$ in $0.5-\mathrm{Hz}$ increments. The primary purpose of this test was to determine the dynamic response frequencies of the balcony. Vibration amplitudes were measured simultaneously at the same seven locations as Condition 1. Measured RMS displacements for associated measurement location groups are shown in Figs. 15-16.

Ambient Excitation - Ambient vibration response, at the same seven measurement locations as in Condition 1, was measured from 17:25 to 18:15. Measurement data, with a response bandwidth of $1.100 \mathrm{~Hz}$ was stored in the Zonic FFT analyzer. The data were then filtered to obtain displacement response in the 10-100- and $20-100-\mathrm{Hz}$ ranges. The RMS displacement amplitudes as a function of clock time for the three bandwidths are shown in Figs. 17-19. Power spectral density plots corresponding to a measurement time of $17: 27$, when there was activity on the balcony, are shown in Figs. 10-24. This specific time was chosen to observe the dynamic characteristics of the balcony. A power spectral density plot of the balcony at 17:49, a time when balcony activity was minimal, is shown in Fig. 25.

\section{DISCUSSION}

\section{Condition 1}

The displacement response (Fig. 3) of the floor at location 4 is fairly constant throughout the frequency range of $20-100 \mathrm{~Hz}$ because the exciter is located on the same floor slab. The attenuation effect of the isolation joints between the column pad and Location 4 can be clearly seen. A la: ,er attenuation is observed between Location 4 and Location 5 even though the transducers are located $\approx 12 \mathrm{in}$. apart, on either side of the isolation joint.

The responses at Location 5, Location 6 (the top surface of the storage ring tunnel), and the storage ring basemat are shown in Fig. 4. The minimum observed amplitude, for most frequencies, is on the storage ring basemat. The response of the storage ring basemat in the $50-60-\mathrm{Hz}$ region is obtained because the ambient vibration level is greater than the forced-excitation level.

The responses of the balcony at two locations and the column pad are shown in Fig. 5. Although the trends at all three locations are similar, the amplitude at the 
end of the balcony is higher than it is in the center of the balcony because the end of the balcony is supported by a roof girder, which is supported by a column.

Attenuation between Location 4, and the storage ring basemat, as a function of frequency is shown in Fig. 6. The data is "approximated" by a power function equation of the form

$$
\mathrm{A}=\mathrm{Kf} \alpha,
$$

where $A$ is the attenuation factor, $\mathrm{K}$ is a statistically determined constant, $\mathrm{f}$ is the frequency in $\mathrm{Hz}$, and $\alpha$ is a statistically determined exponent. The curve-fit equation is given on Fig. 6, where y represents the attenuation function $A$ and $x$ represents the frequency $f$. [Note: On subsequent attenuation-factor-versusfrequency plots (Figs. 7-8), corresponding curve-fit equations are also given.] The attenuation factor between Location 5 and the storage ring basemat is shown in Fig. 7; its value is considerably greater than that obtained at Location 4 relative to the storage ring basemat. This indicates that the isolation joint between the RFextraction-wing floor and the storage ring roof is very effective in minimizing vibration coupling between the floor and storage ring basemat.

The attenuation factors between two isolation joints, one between the column pad and the RF-extraction-wing floor (Location 4) and the other, between the storage ring roof (Location 5) and the RF-extraction-wing floor (Location 4) are shown in Fig. 8. The largest attenuation (smallest attenuation factor) is between the storage ring roof and the RF-extraction-wing floor.

\section{Condition 2}

The measured response of the center and end of the balcony and of the column pad with forced excitation of the balcony at the exciter location shown in Fig. 2, is given in Fig. 9. Although the small applied-force level ( 0.5 pounds RMS) is sufficient to excite the balcony, the large attenuation between the balcony and column pad result in very small displacement of the column pad. A considerable portion of the column pad displacement is the result of ambient excitation.

The responses obtained at the end of the balcony and at Locations 4 and 5 are shown in Fig. 10. Again, because the attenuation is large, the responses at Locations 4 and 5 can be attributed to ambient excitation.

Similar responses are observed on the top surface of the storage ring (Location 6) and the storage ring basemat (Fig. 11), with the majority of the response due to ambient excitation. 
Calculated attenuation factors betv yen the various measurement locations are shown in Figs. 12-14. Because all of the attenuation factors include a significant ambient displacement response, they cannot be considered accurate. However, the attenuation factor for the storage ring basemat relative to the end of the balcony, Fig. 14, can be used as a conservative approximation of the attenuation between the balcony and basemat.

\section{Condition 3}

The measurements for Conditions 1 and 2 address the various responses and attenuations at the higher frequencies, i.e., $>20 \mathrm{~Hz}$. The measurement objective of the tests under Condition 3 was to determine the significant low-frequency resonances of the balcony. The approximate measured resonant frequencies are 5, 7 , and $9.5 \mathrm{~Hz}$ (Fig. 15). There is a possibility that the resonant frequency of the pump seismic block isolator will coincide with a balcony resonance. Although the control system of the storage ring magnet feedback is designed to compensate for low-frequency displacements, a large low-frequency response could exceed its dynamic range. However, because the coupling between the storage ring basemat and the balcony is low, it is extremely unlikely that the dynamic range of the control system will be exceeded. The low displacement response of the storage ring basemat is the result of ambient excitation, not a response to the exciter.

\section{Ambient Excitation}

The measured RMS displacement for bandwidths of $1.100 \mathrm{~Hz}, 10-100 \mathrm{~Hz}$, and $20-100 \mathrm{~Hz}$ for the seven measurement locations are shown in Figs. 17, 18, and 19, respectively. The measurements were taken from $17: 24$ to $18: 15$, on July 28,1993 , at a time when site activity was low; however, there was some activity on the balcony, where the exciter was being placed.

\section{$1 \cdot 100 \mathrm{~Hz}$}

The largest measured displacements were on the balcony, which is a very flexible structure. The top surface of the storage ring tunnel, which is associated with a very large low-frequency response (see Fig. 23), exhibited a large displacement. It is uncertain if this is a transducer problem or an actual displacement, inasmuch as the transducers are sensitive to thermal gradients. The displacements at Locations 4 and 5 are basically equal in amplitude and follow the same trend. The lowest displacement level is again on the storage ring basemat. 


\section{$10 \cdot 1.00 \mathrm{~Hz}$}

The measured displacement amplituce at all locations is considerably lower (see Fig. 18) than the displacement amplitude at 1-100 Hz, shown in Fig. 17. This finding indicates that a large displacement contribution is present in the $1.10 \mathrm{~Hz}$ band, a frequency range where the feedback control system is effective. The balcony still exhibits the largest displacement. The remaining displacements tend to group around the 0.01 micron level, with the column pad and the storage ring basemat being the highest. However, they are all within acceptable limits.

\subsection{Hz}

As shown in Fig. 19, at $20-100 \mathrm{~Hz}$, the amplitude levels are smaller than those for the previous bandwidths, with the balcony still being the largest. Of interest are the amplitude levels of the storage ring top surface and basemat, which are higher than those of the floor and column pad, and may be the result of low internal attenuation of vibration at higher frequencies of large massive concrete structures, such as the storage ring tunnel and basemat.

\section{Power Spectral Density Plots}

Figures 20-24 show the spectral content of the RMS displacements corresponding to a clock time of $17: 27$, a time with some activity on the balcony. For comparison, Fig. 25 shows the response of the balcony at $17: 49$, corresponding to a time of minimal activity on the balcony.

The balcony respunse (Fig. 20) shows two large-amplitude responses at $3 \mathrm{~Hz}$ and $4.6 \mathrm{~Hz}$. Although the response at $3 \mathrm{~Hz}$ has not been previously identified, the response at $4.6 \mathrm{~Hz}$ lies within the envelope of the response at $4.9 \mathrm{~Hz}$, which was observed in Fig. 25 and corresponds to the response at $5 \mathrm{~Hz}$ that was observed in the forced-excitation measurements of Figs. 15 and 16.

The response of the end of the balcony and the column pad are shown in Fig. 21. Although the amplitudes associated with the column pad are considerably lower than those of the end of the balcony, the balcony response frequencies of $3 \mathrm{~Hz}$ and $4.6 \mathrm{~Hz}$ are observed on the column pad.

The response at Locations 4 and 5, shown in Fig. 22, indicates that the amplitudes and frequency content of both are basically equal. This contrasts with the forced-excitation response, where considerable attenuation was observed in the Location-5 amplitude. This contrast is attributed to the excitation source; the source of the forced-excitation response measurements is located at a specific 
location on the floor. For these measurements, the source is far-field ambient excitation, which is approximately equal at both Locations 4 and 5.

The response of the top surface of the storage ring and basemat are shown in Fig. 23. Other than the large low-frequency response of the top surface of the storage ring, the responses are basically the same. It is uncertain if the large lowfrequency response is an actual response; however, with the good amplitude and spectral correlation at higher frequencies, the authors suspect that it is a seismometer problem, such as a thermal gradient.

The response of the storage ring basemat and balcony are shown in Fig. 24. Several balcony frequencies are seen on the basemat response: $3 \mathrm{~Hz}, 4.6 \mathrm{~Hz}$. Although these balcony frequencies were observed, the amplitudes on the basemat. are very small.

The response of the balcony during a quiet period is shown in Fig. 25. The basic difference between this response and that shown in Fig. 20, during balcony activity, is the absence of the response at $3 \mathrm{~Hz}$ and a slightly higher mid-frequency response $(30-70 \mathrm{~Hz})$ observed on the end of the balcony.

\section{COMMENTS/CONCLUSIONS}

Rotating machinery, directly coupled to electric motors, typically rotates at slightly less than synchronous speeds of 1800 and $3600 \mathrm{rpm}$, which correspond to frequencies slightly less than 30 and $60 \mathrm{~Hz}$, respectively. The attenuation equations shown in the attenuation figures are evaluated for frequencies of 30 and $60 \mathrm{~Hz}$, for exciter locations corresponding to Conditions 1 and 2; see Tables 1 and 2. The attenuation values shown in the tables should be considered approximations because no consideration of the specific mode shapes were taken into account. However, they provide valuable insight into the various attenuations of the structures. The attenuation values of Table 2 are more uncertain because of the contamination of the forced excitation response by ambient excitation.

The spectral content of the vertical displacement of the storage ring basemat has increased considerably from the February 2, 1993, measurements; see Fig. 26. The corresponding increase in displacement, for a frequency range of $10-100 \mathrm{~Hz}$, is approximately a factor of 3 . Some of the increases is due to a small amount of activity on the basemat when the present measurements were made.

Several conclusions can be drawn. 
- The coupling between the balcony and the storage ring basemat is low. In addition, the balcony acts as a "mechanical filter" at higher frequencies.

- The coupling between the RF-extraction-wing floor and storage ring basemat is reasonably low, and shows increased attenuation at higher frequencies.

- The spectral content of the ambient displacement response has increased considerably, an indication of more excitation sources.

- The ambient displacement amplitude response of the basemat has increased from previous measurements, however the levels are considered acceptable.

- Because the coupling between the RF-extraction-wing floor and the storage ring basemat and between the balcony and the storage ring basemat was small, placement of additional pumps (either on the floor or the balcony) is not critical, providing their vibrational unbalance is small, typically 0.5 pound force at frequencies $>28 \mathrm{~Hz}$.

\section{REFERENCES}

1. M. W. Wambsganss, J. A. Jendrzejczyk, and S. S. Chen, "Vibration Study of the APS Magnet Support Assemblies," APS/IN/VIB/90-3, Nov. 1990. 
Table 1. Attenuation as a function of frequency for various locations with forced excitation on the RF-extraction-wing floor

\begin{tabular}{ccc}
\hline $\begin{array}{c}\text { Isolation Joint or } \\
\text { Location }\end{array}$ & $\begin{array}{c}\text { Attenuation } \\
\text { at } 30 \mathrm{~Hz}\end{array}$ & $\begin{array}{c}\text { Attenuation } \\
\text { at } 60 \mathrm{~Hz}\end{array}$ \\
\hline Location 5/Location 4 & 0.208 & 0.070 \\
Column Pad/Location 4 & 0.452 & 0.194 \\
SR Basemat/Location 4 & 0.120 & 0.026 \\
SR Basemat/Location 5 & 0.107 & 0.068 \\
\hline
\end{tabular}


Table 2. Attenuation as a function of frequency for various locations with forced excitation on the balcony

\begin{tabular}{ccc}
\hline $\begin{array}{c}\text { Isolation Joint or } \\
\text { Location }\end{array}$ & $\begin{array}{c}\text { Attenuation } \\
\text { at } 30 \mathrm{~Hz}\end{array}$ & $\begin{array}{c}\text { Attenuation } \\
\text { at } 60 \mathrm{~Hz}\end{array}$ \\
\hline Location 5/Location 4 & 0.671 & 0.479 \\
Column Pad/Balcony End & 0.005 & 0.007 \\
SR Basemat/Balcony End & 0.001 & 0.0005 \\
\hline
\end{tabular}


Accelerometer location 6, on top surface of Storage

Ring roof

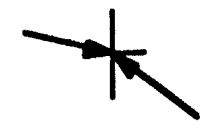

Accelerometer location 7, on Basemat, directly below acceleromater 6

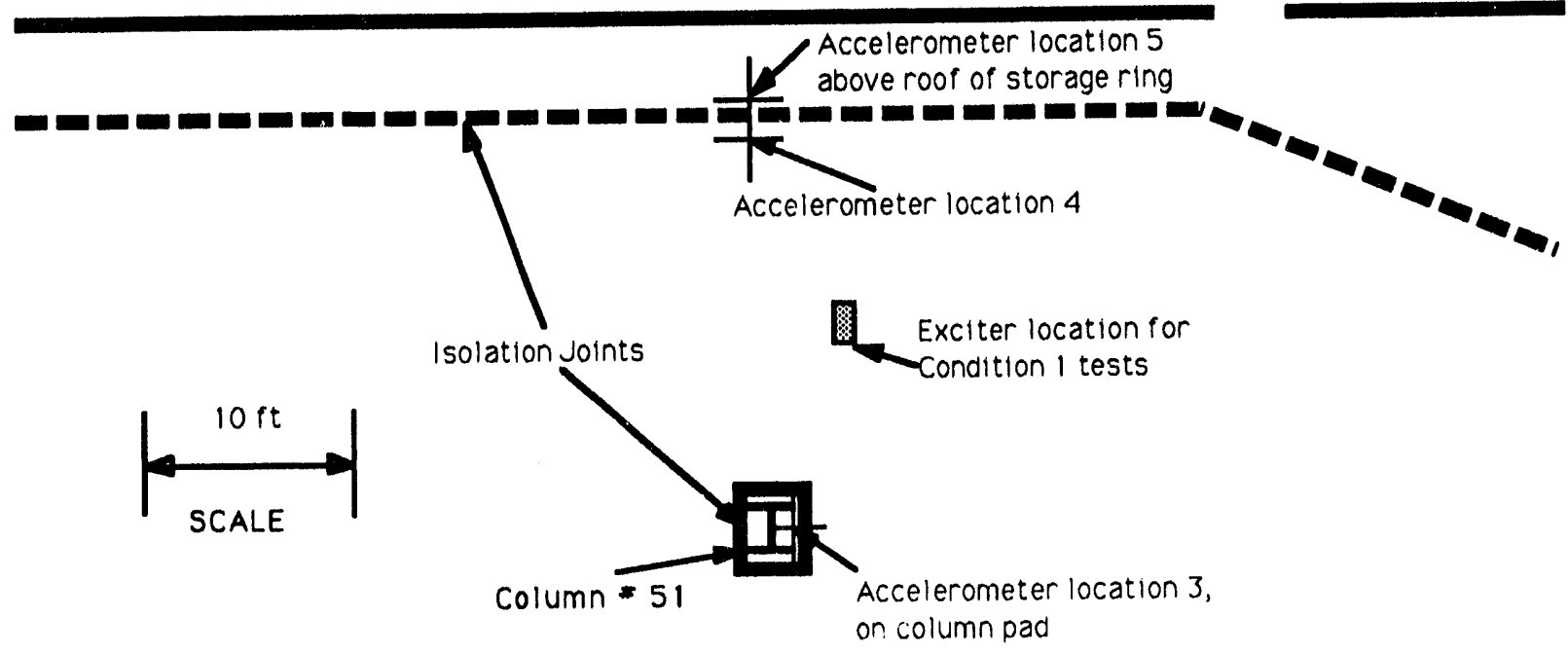

NOTE: All accelerometers are oriented vertically. Exciter oriented vertically.

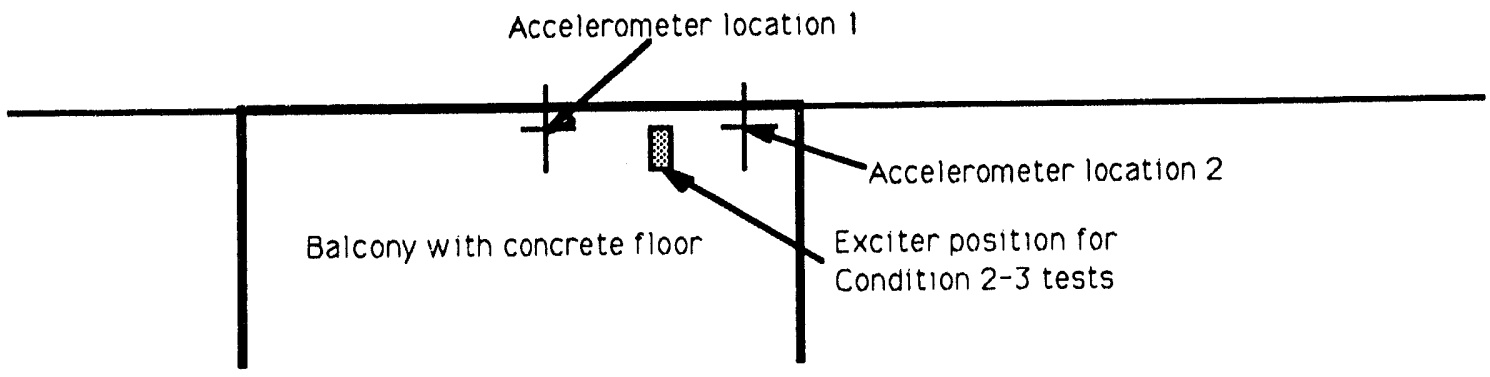

Fig. 1. Site layout for basic measurements 


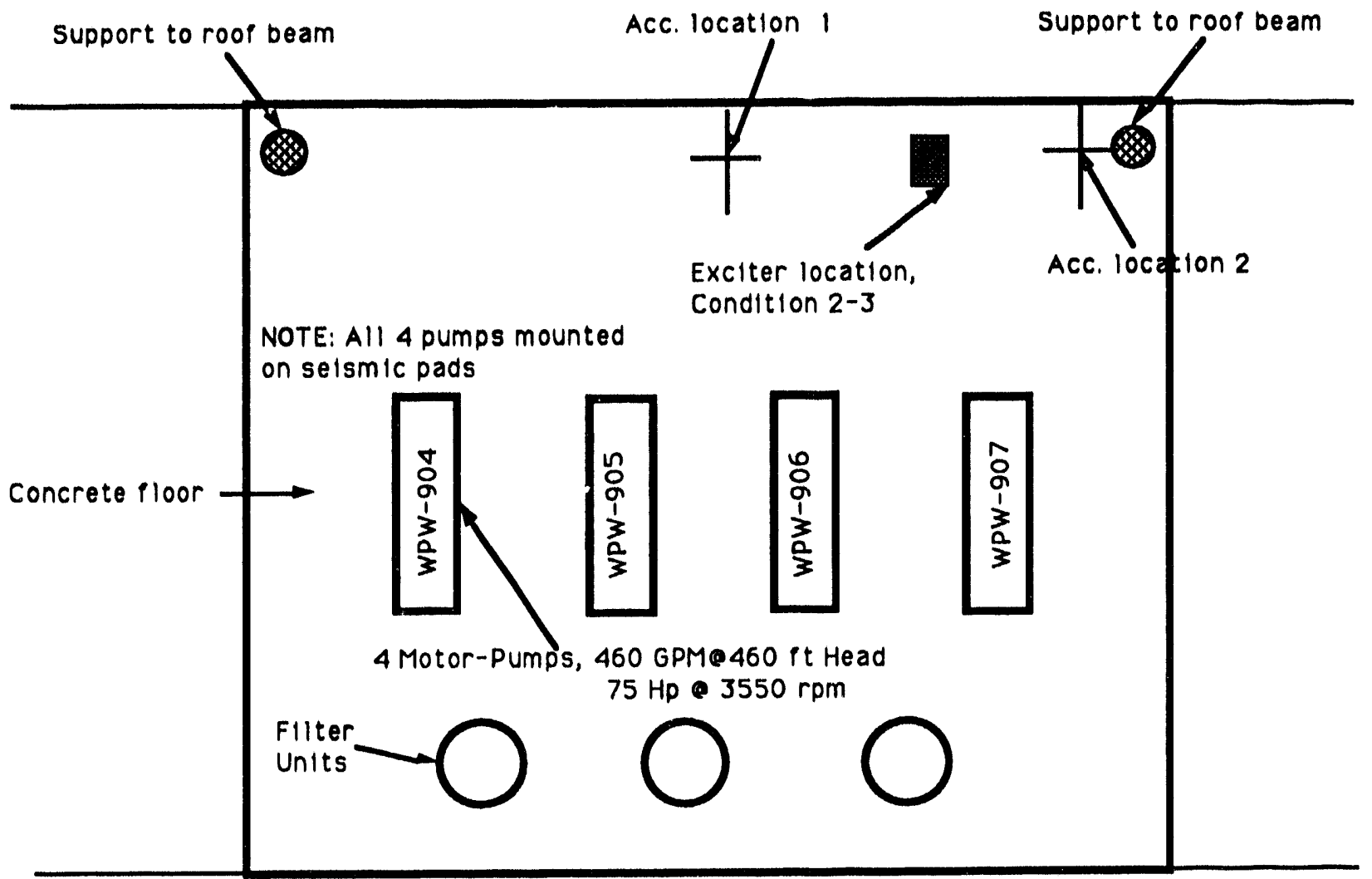

South wall of RF Extraction Wing

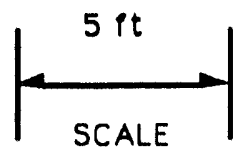

Fig. 2. Balcony detail, showing pumps and filter tanks 


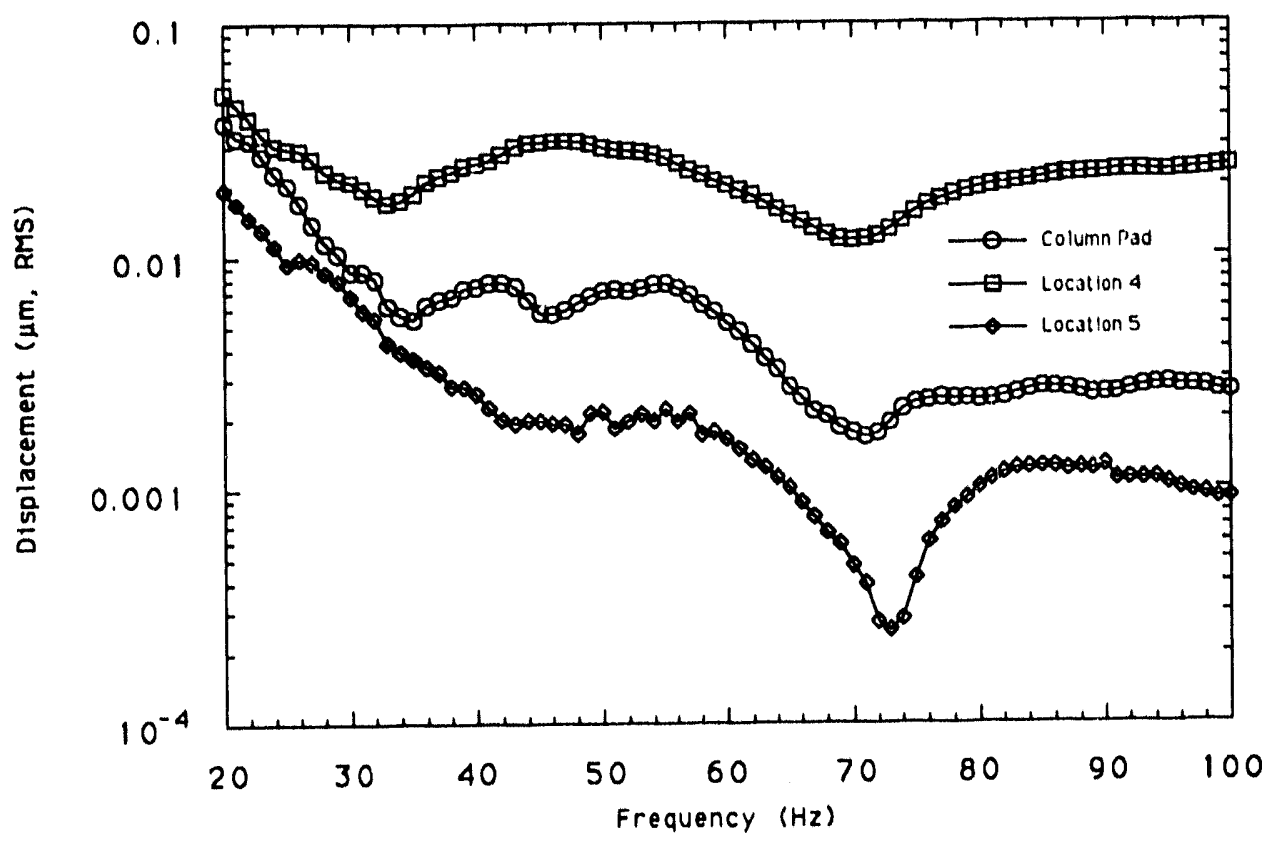

Fig. 3. Response at column pad and Locations 4 and 5 to forced excitation of RF-extraction-wing floor

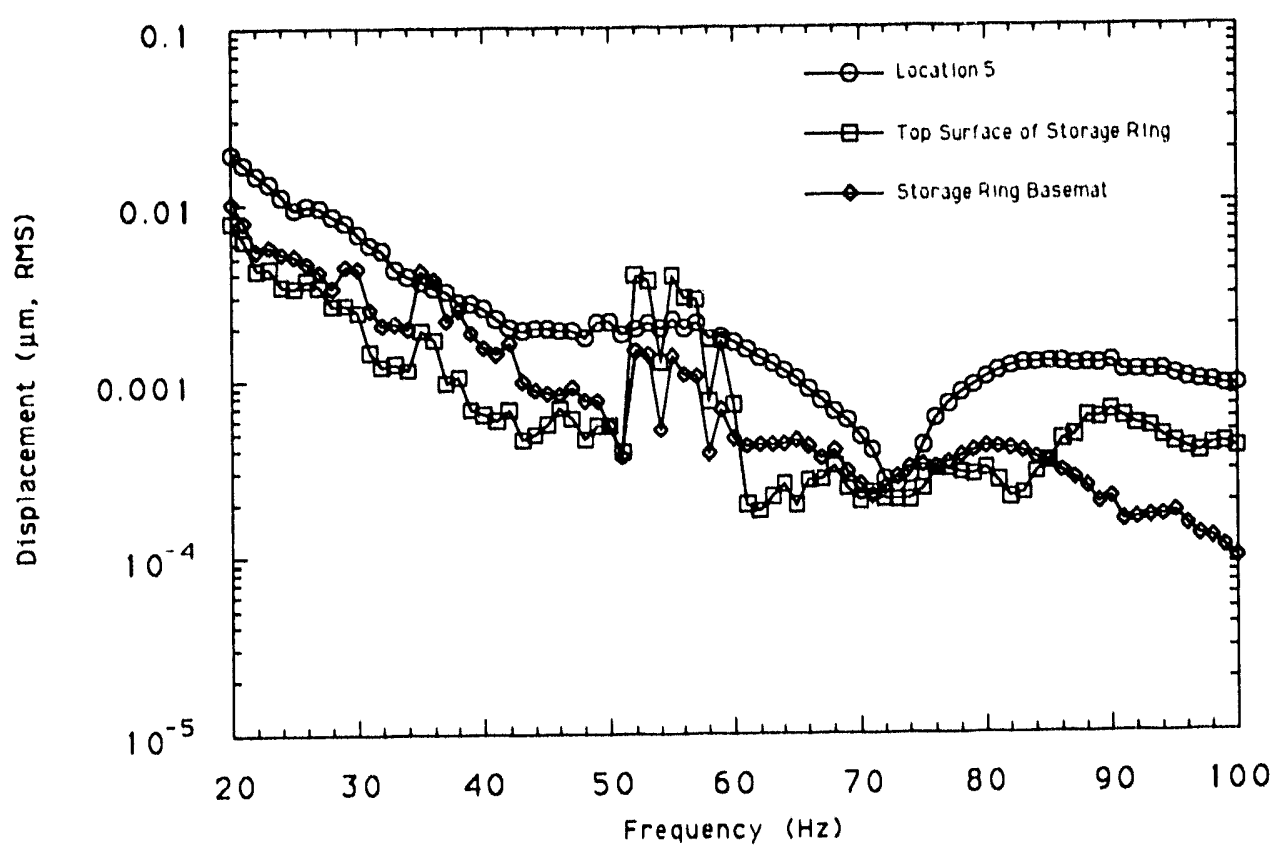

Fig. 4. Response at Location 5, at the top surface of the storage ring, and at storage ring basemat to forced excitation of $\mathrm{RF}$-extraction-wing floor 


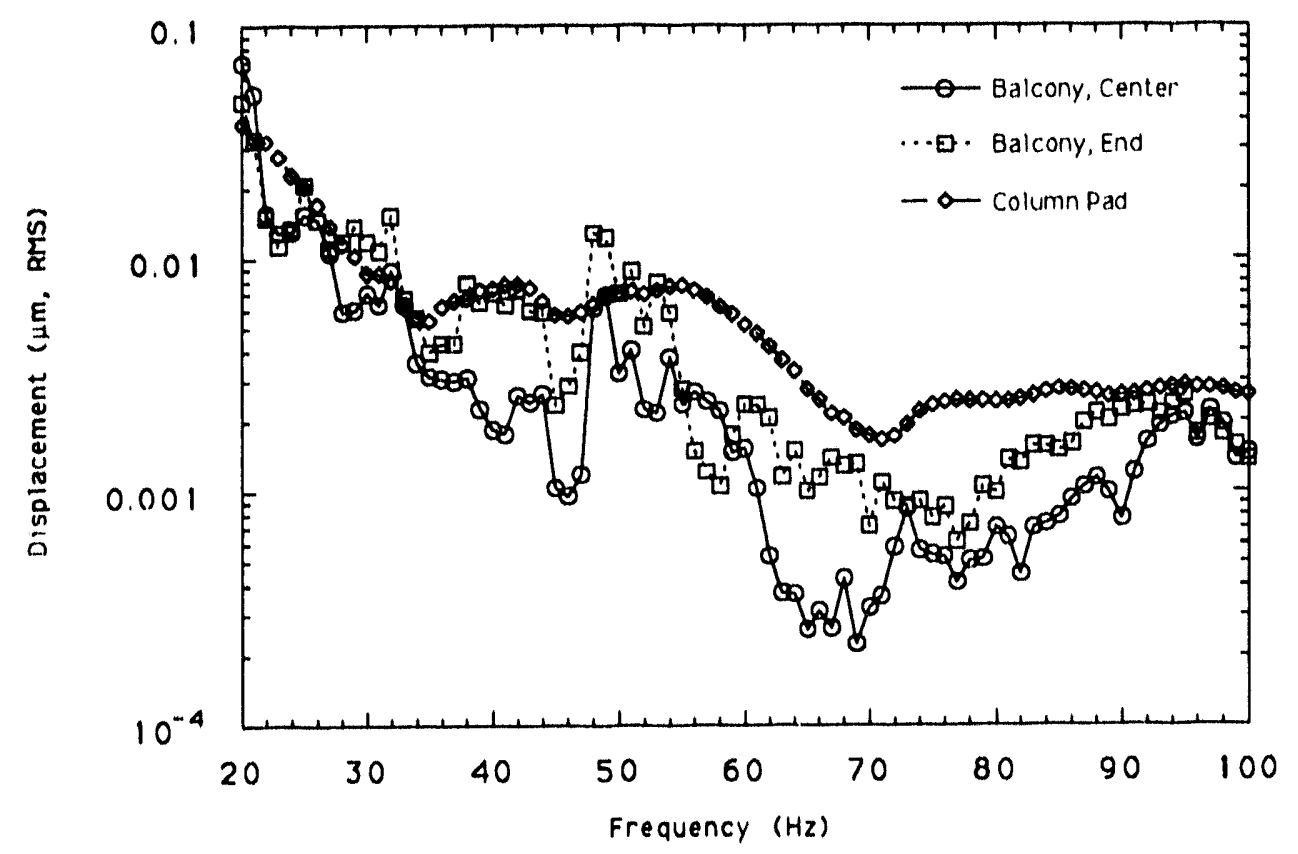

Fig. 5. Response of balcony at two locations and column pad to forced excitation of RF Extraction wing floor

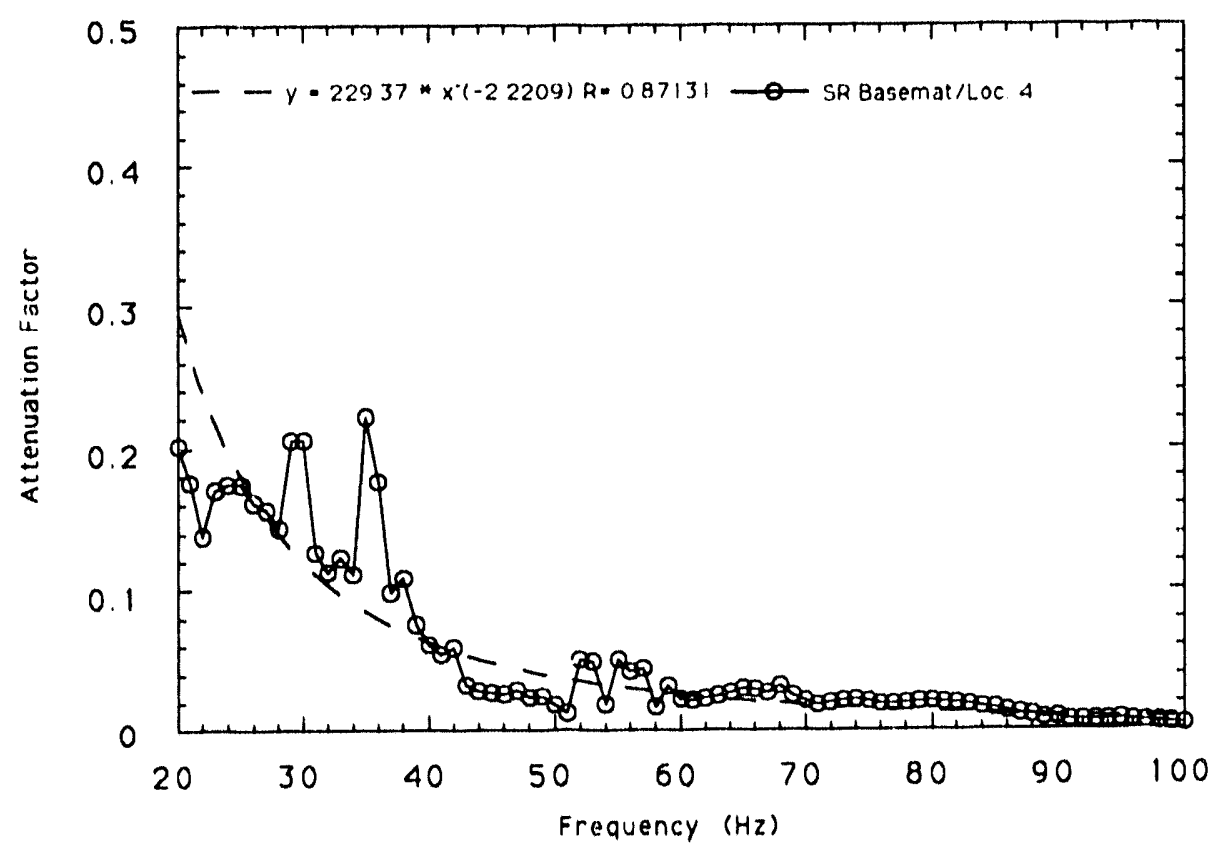

Fig. 6.Attenuation between storage ring basemat and Location 4 with forced excitation of RF-extraction-wing floor 


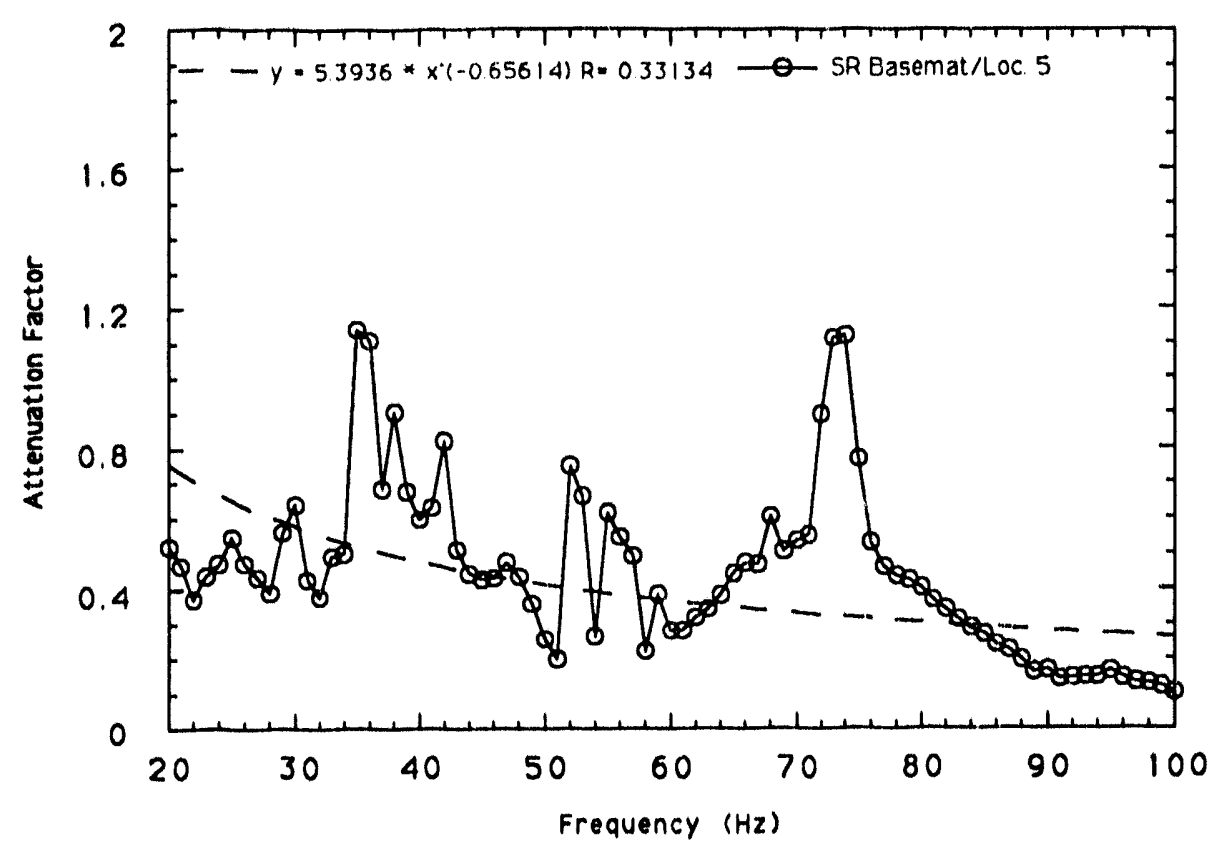

Fig. 7. Attenuation between storage ring basemat and Location 5 with forced excitation of RF-extraction-wing floor

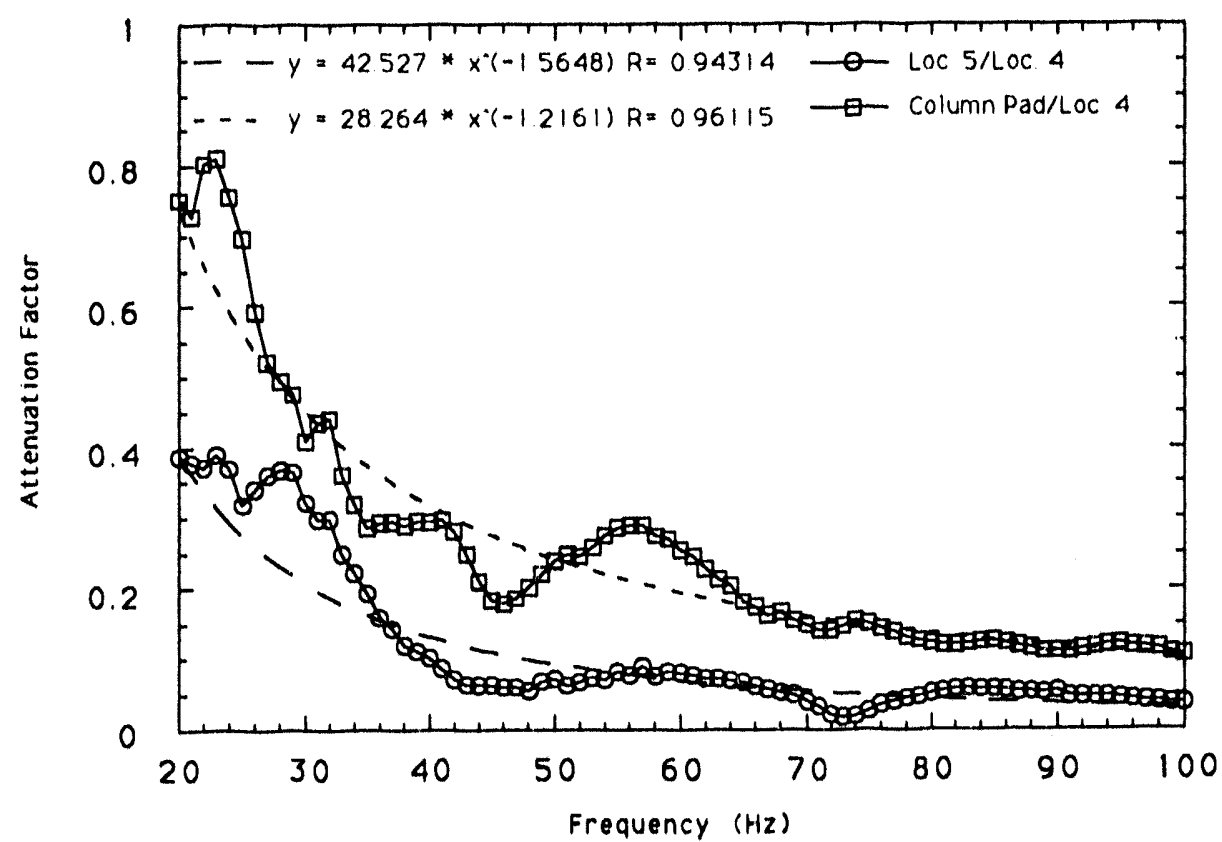

Fig. 8. Attenuation between Location 5 and Location 4 , and between column pad and Location 4 with forced excitation of RF-extraction-wing floor 


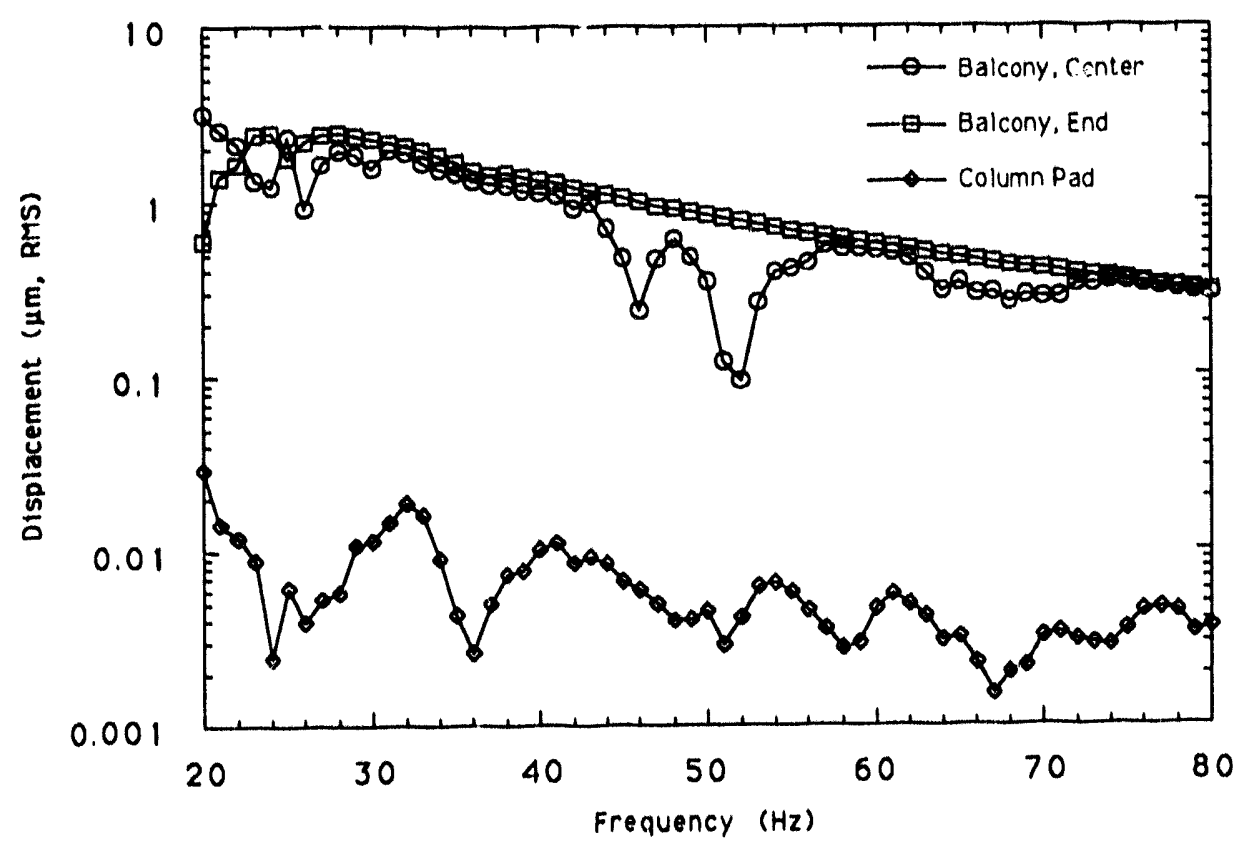

Fig. 9. Response of balcony at two locations and column pad to forced excitation of balcony

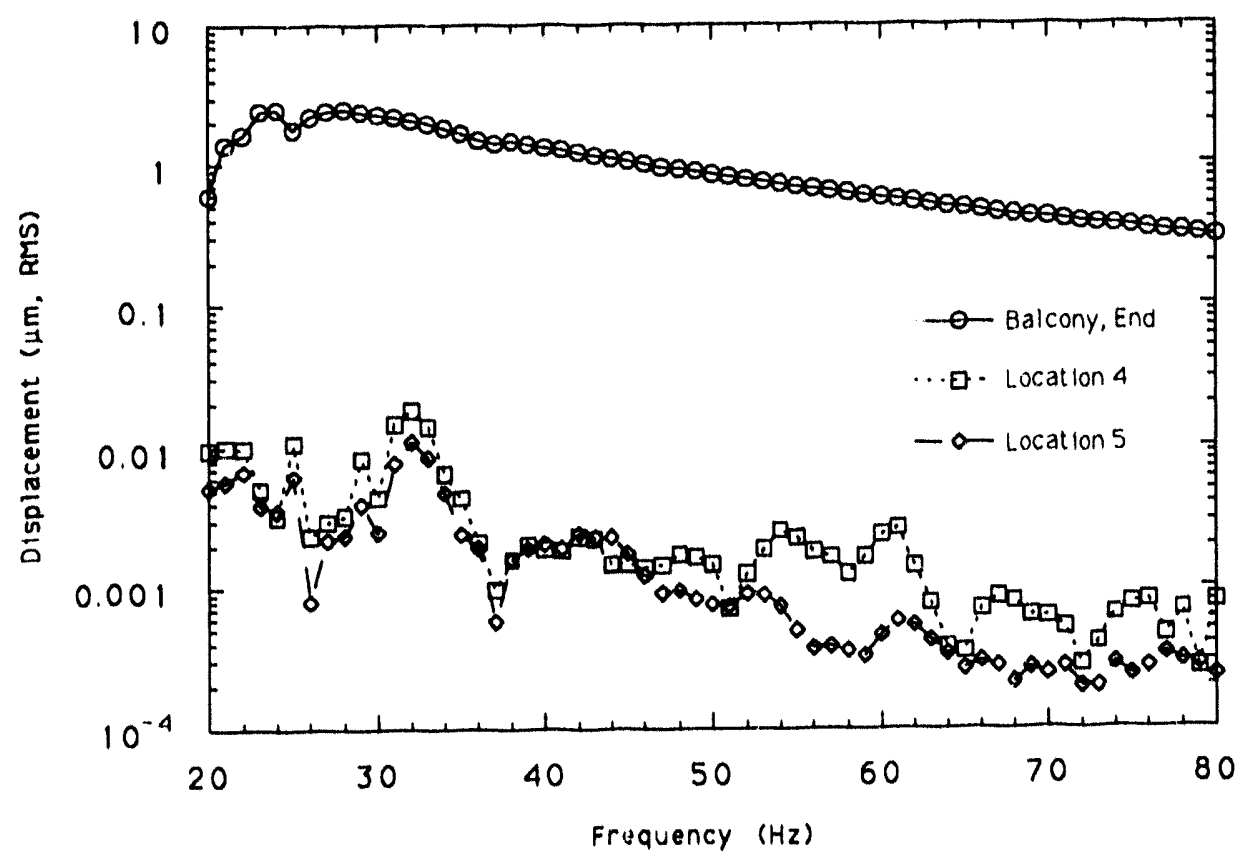

Fig. 10. Responses obtained at end of balcony and at Locations 4 and 5 to forced excitation of balcony 


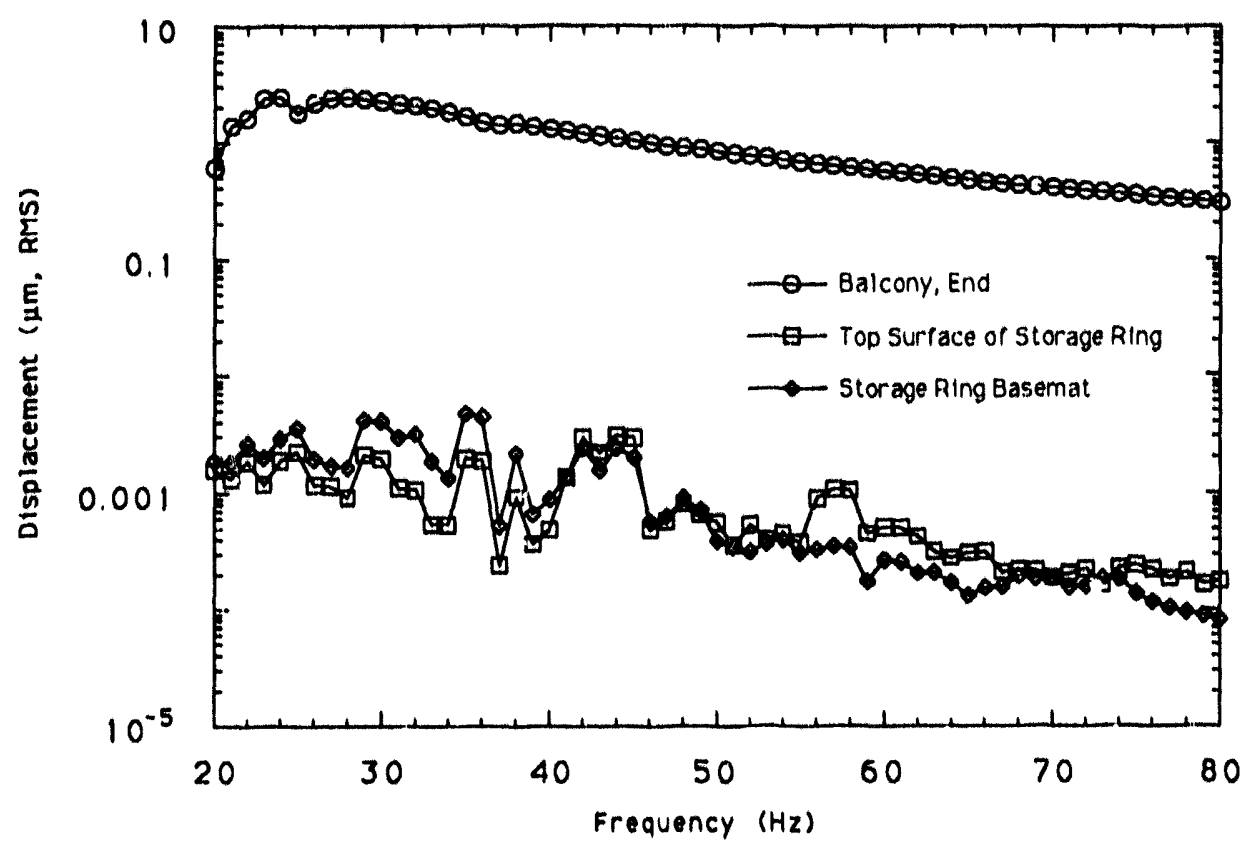

Fig. 11. Balcony and storage ring response to forced excitation of balcony

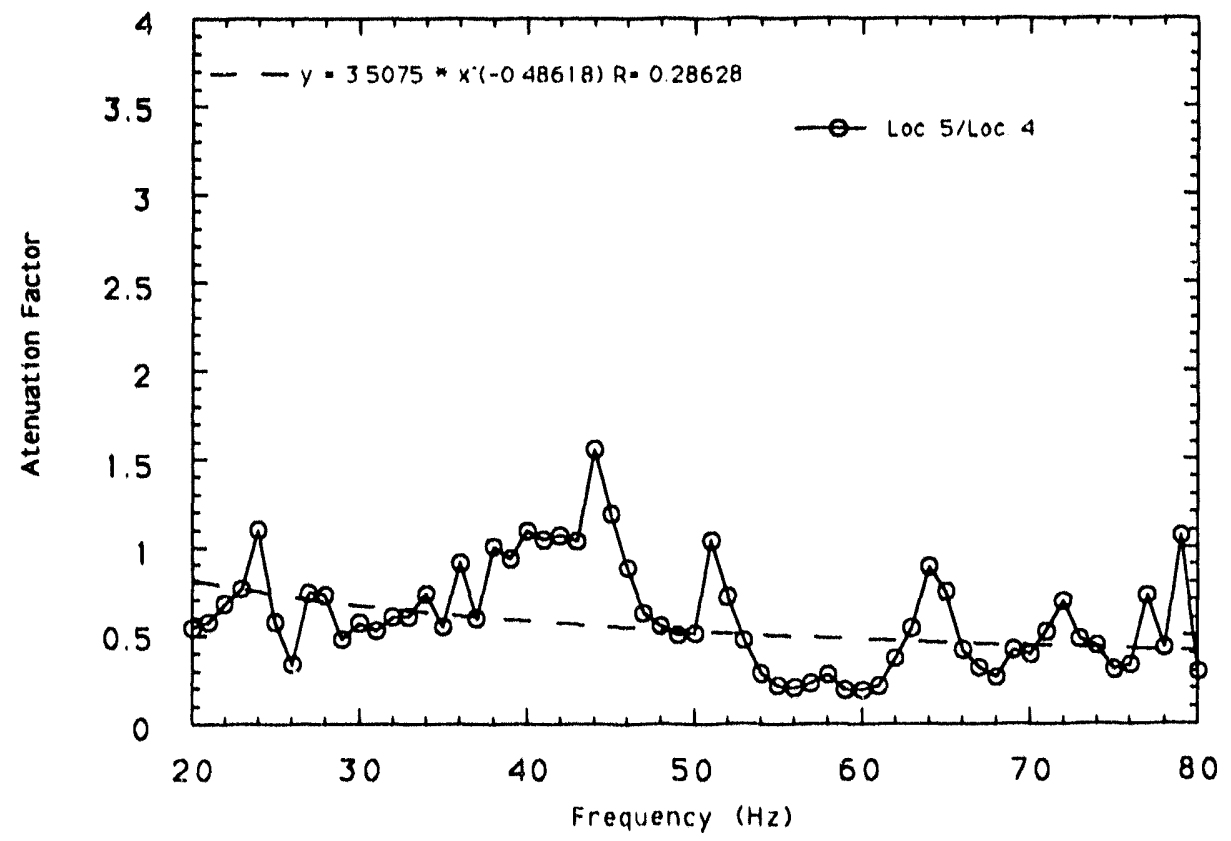

Fig. 12. Attenuation between Locations 5 and 4 with forced excitation of balcony 


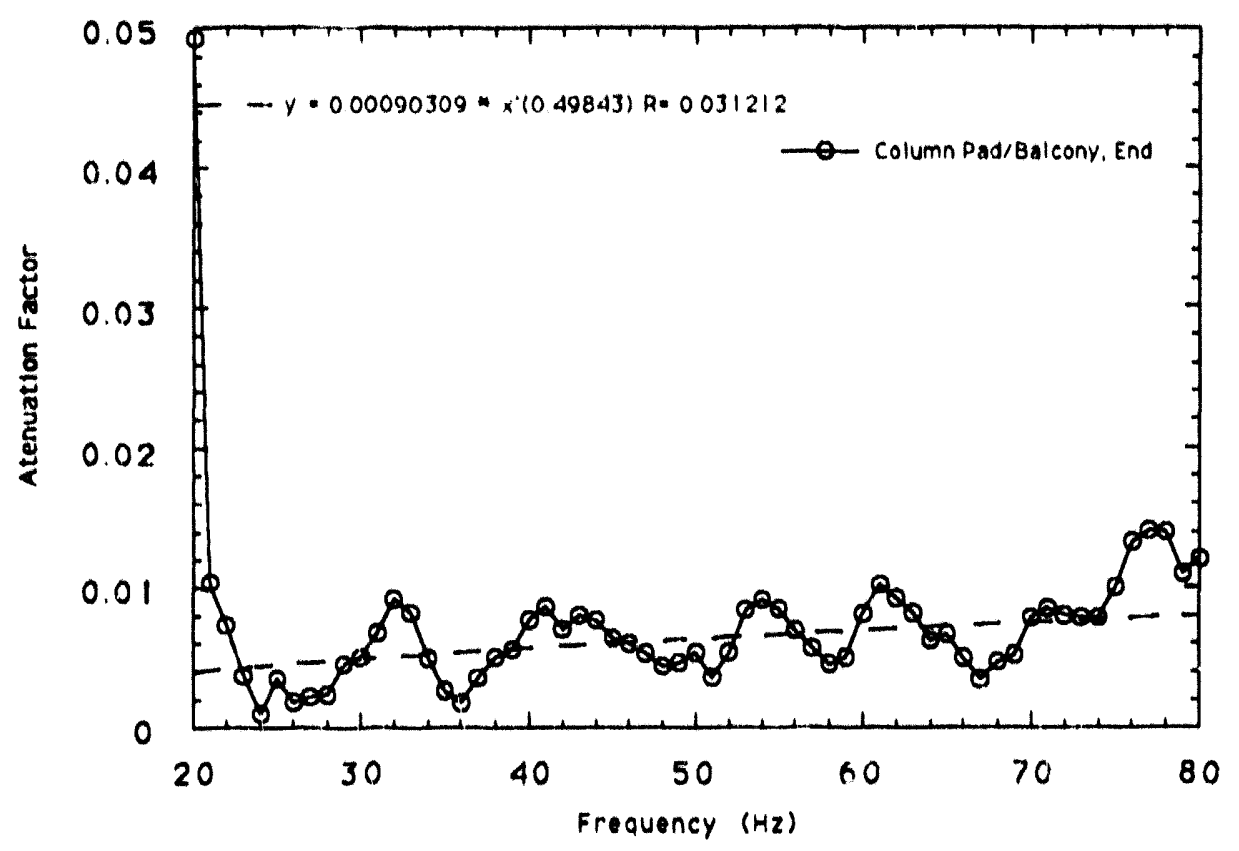

Fig. 13. Attenuation between column pad and end of balcony with forced excitation of balcony

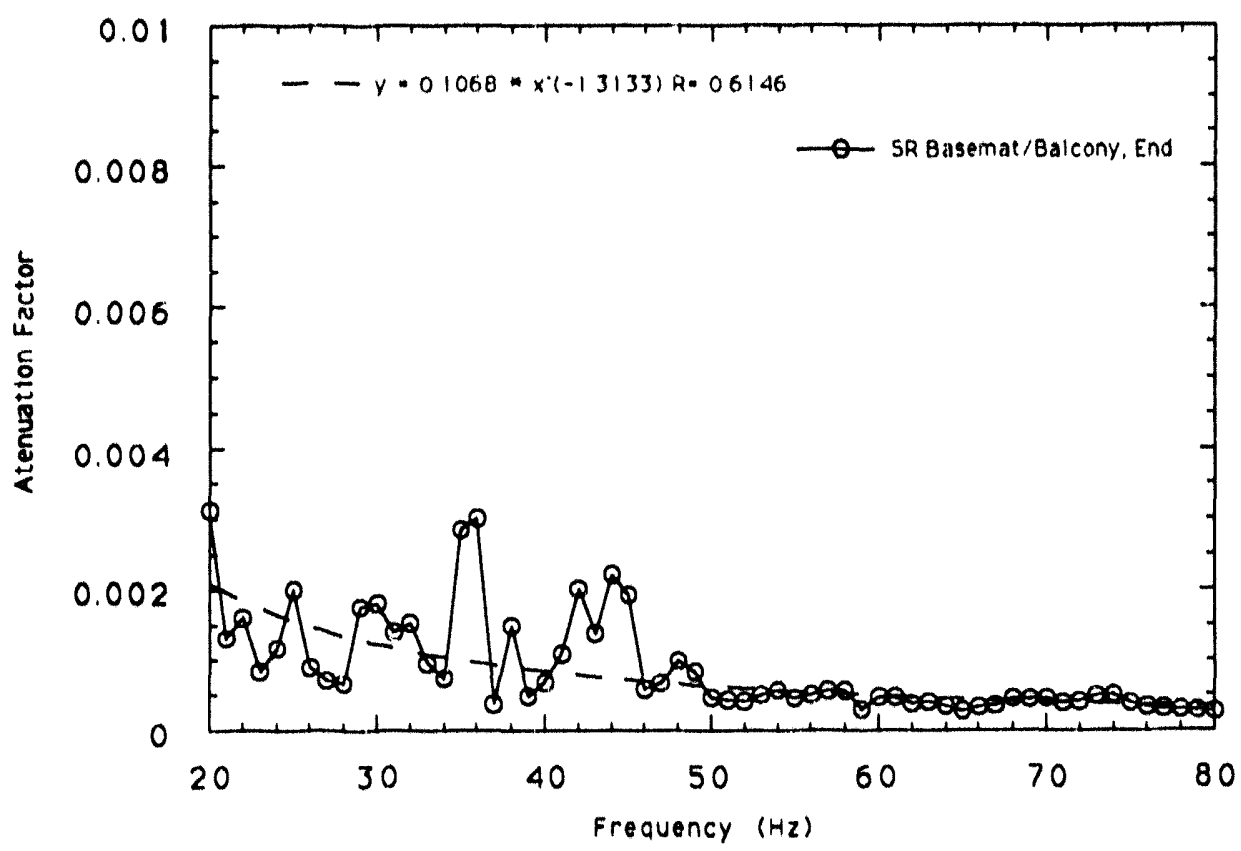

Fig. 14. Attenuation between storage ring basemat and end of balcony with forced excitation of balcony 


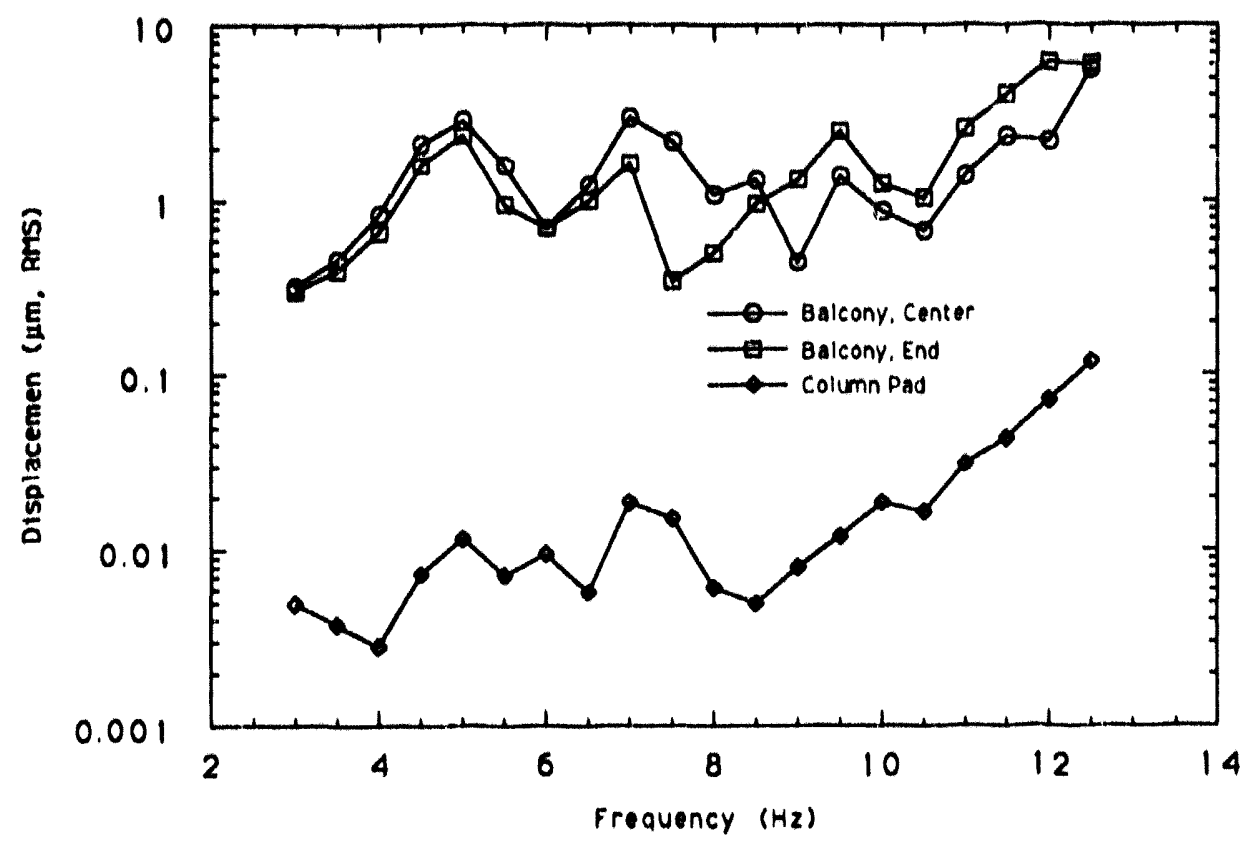

Fig. 15. Dynamic response of balcony at two locations and column pad to low-frequency excitation of balcony

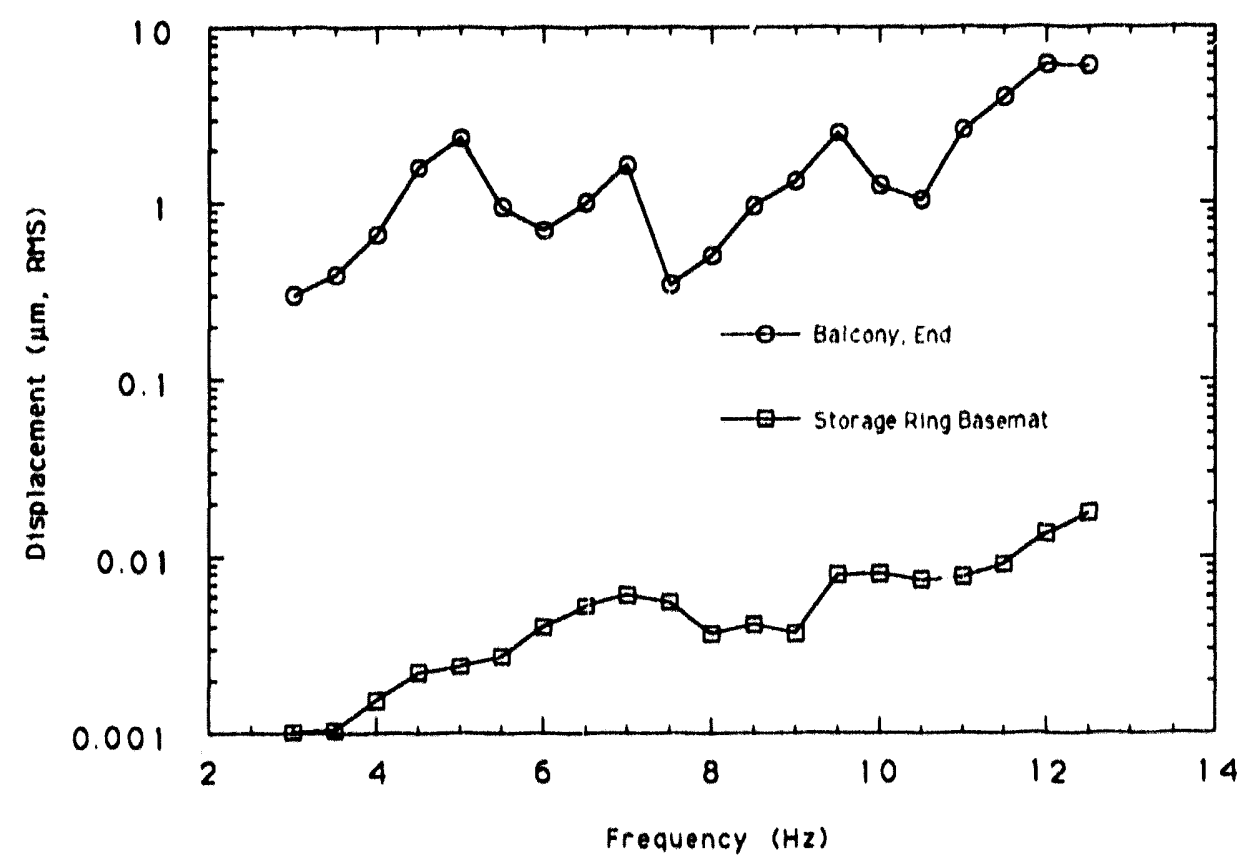

Fig. 16. Dynamic response of end of balcony and storage ring basemat to low-frequency excitation on balcony 


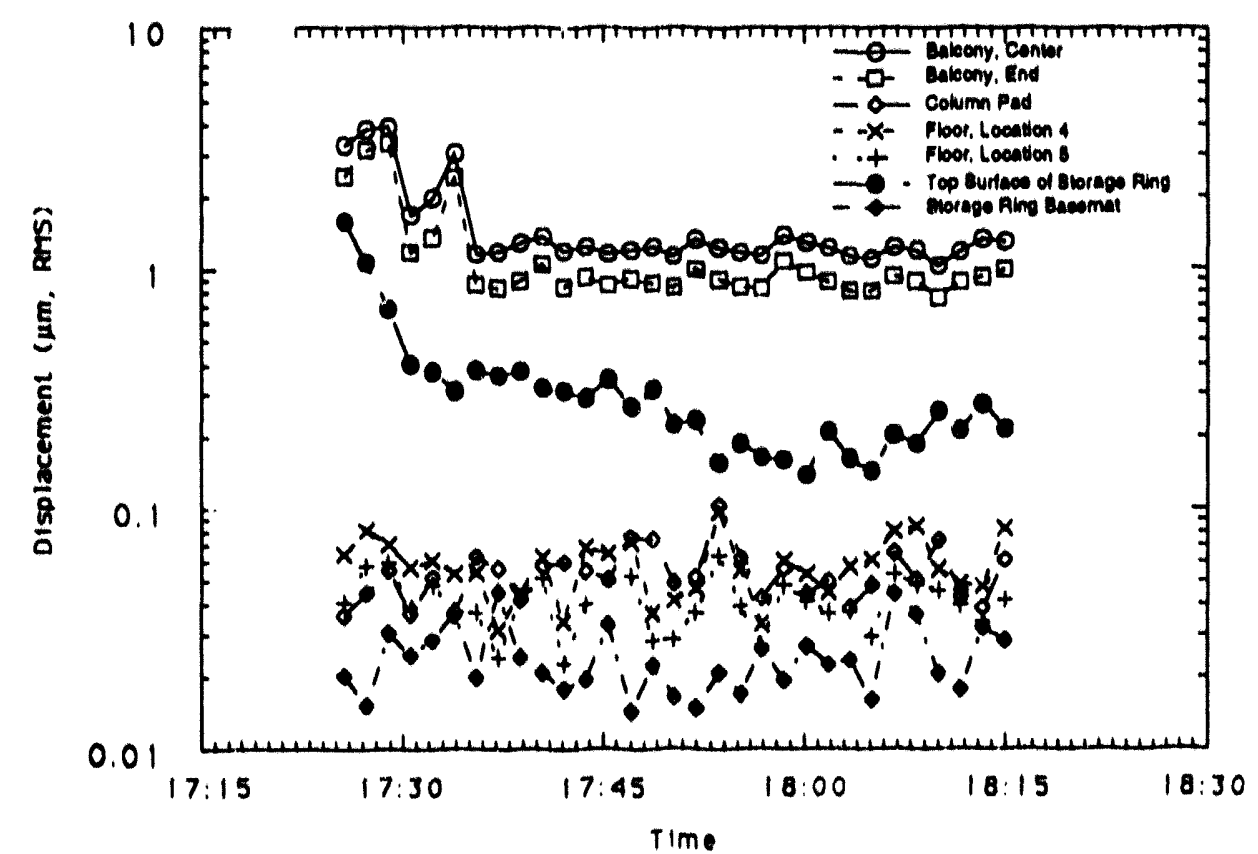

Fig. 17. Dynamic response of the balcony at two locations, the column pad, the RF-extraction-wing floor, and the basemat and top surface of the storage ring to ambient vibration, $1-100 \mathrm{~Hz}$ band

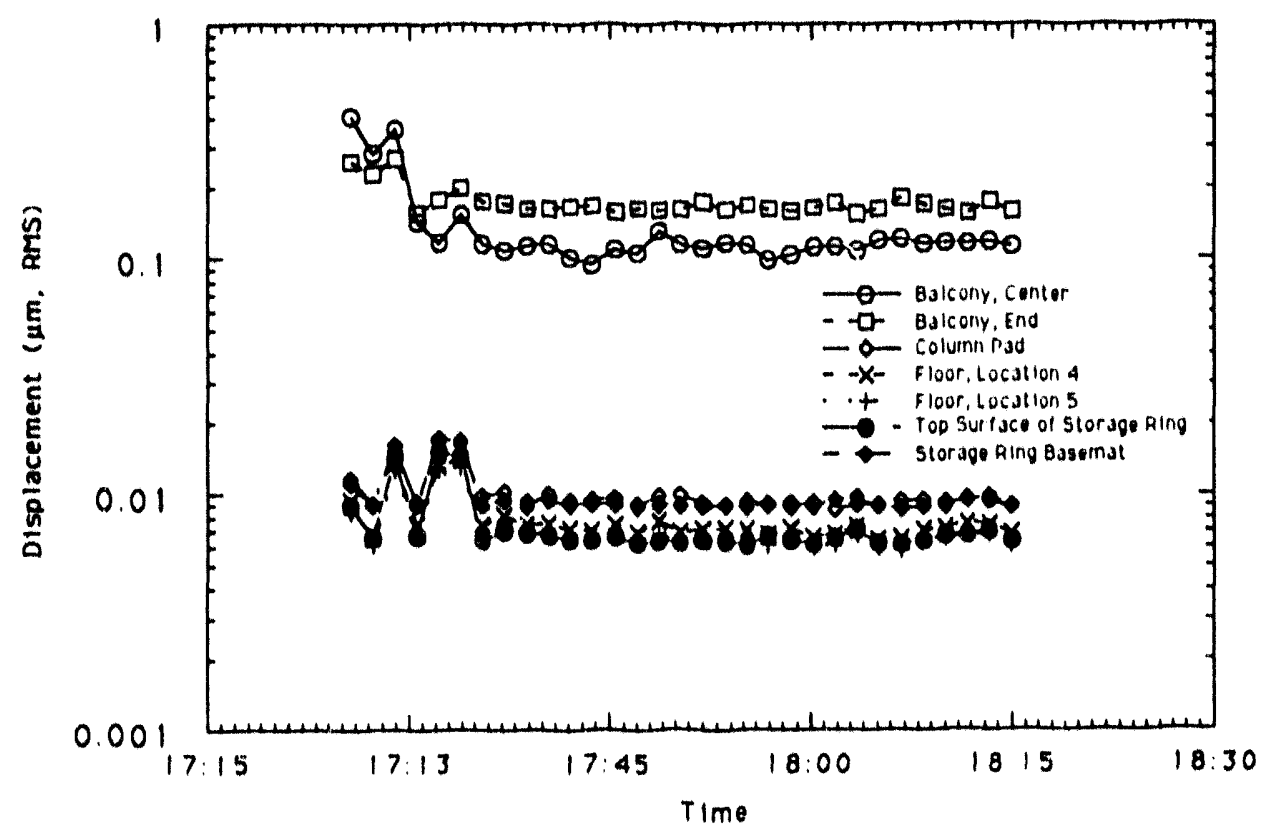

Fig. 18. Dynamic response of the bulcony at two locations, the column pad, the RF-extraction-wing floor, and the basemat and top surface of the storage ring to ambient vibration, $10-100 \mathrm{~Hz}$ hand 


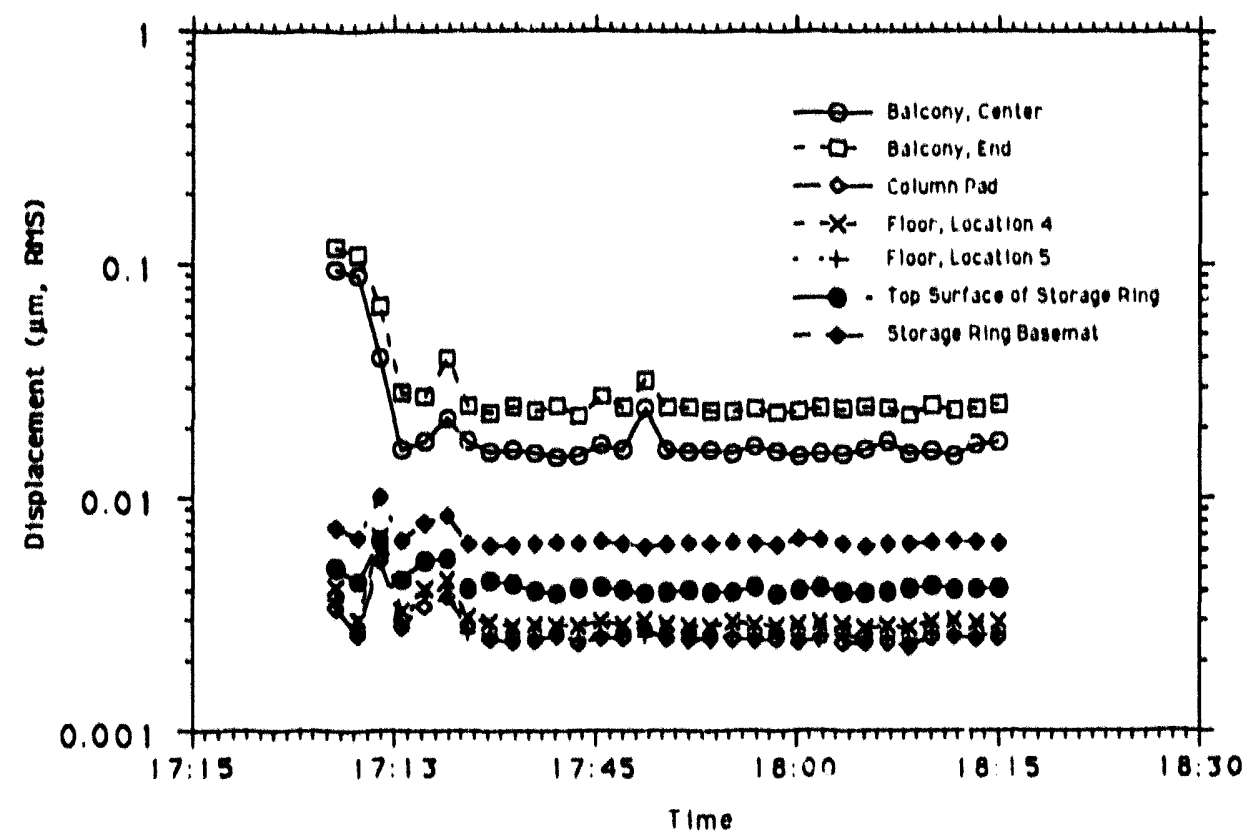

Fig. 19. Dynamic response of the balcony at two locations, the column pad, the RF-extraction-wing floor, and the basemat and the top surface of the storage ring to ambient vibration, $20-100 \mathrm{~Hz}$ band

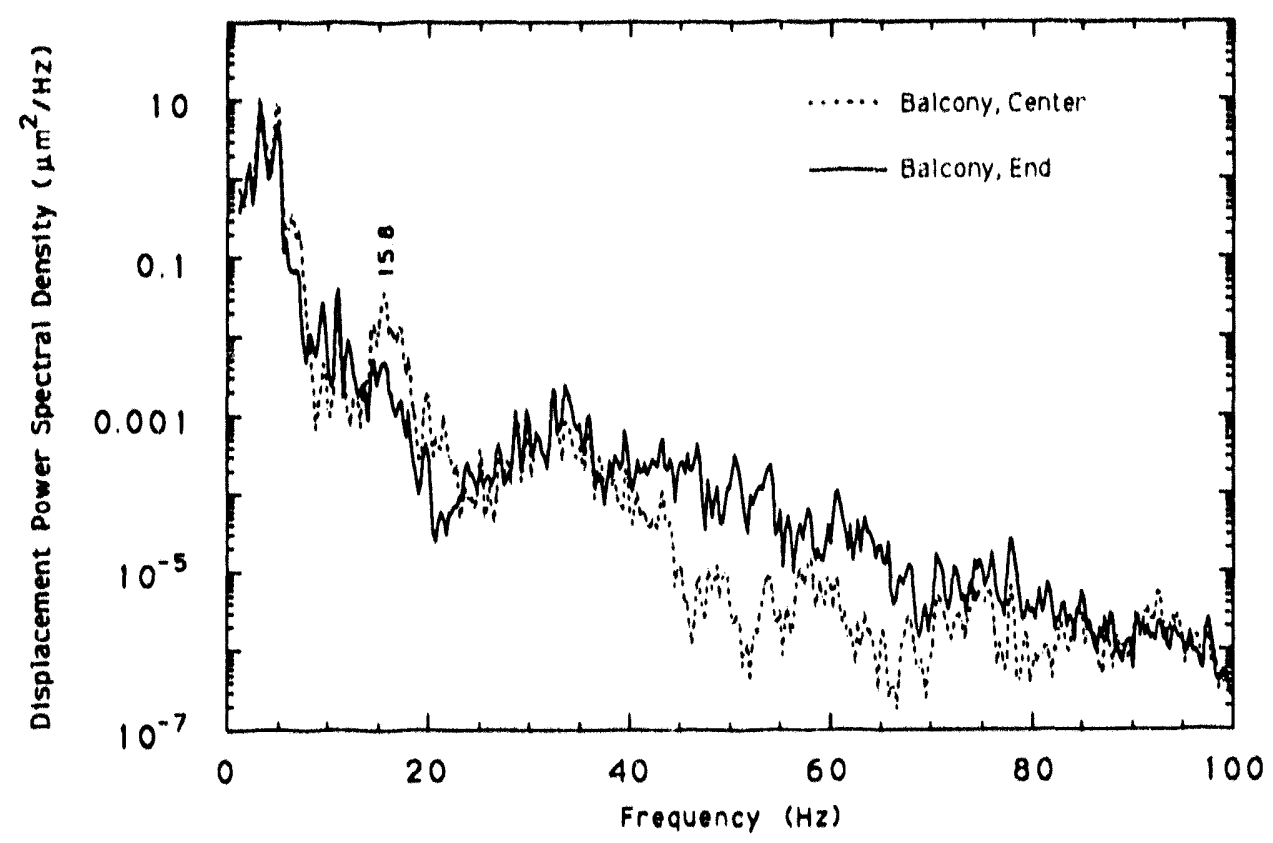

Fig. 20. Spectral density of balcony displacement with ambient excitation when activity was present on balcony 


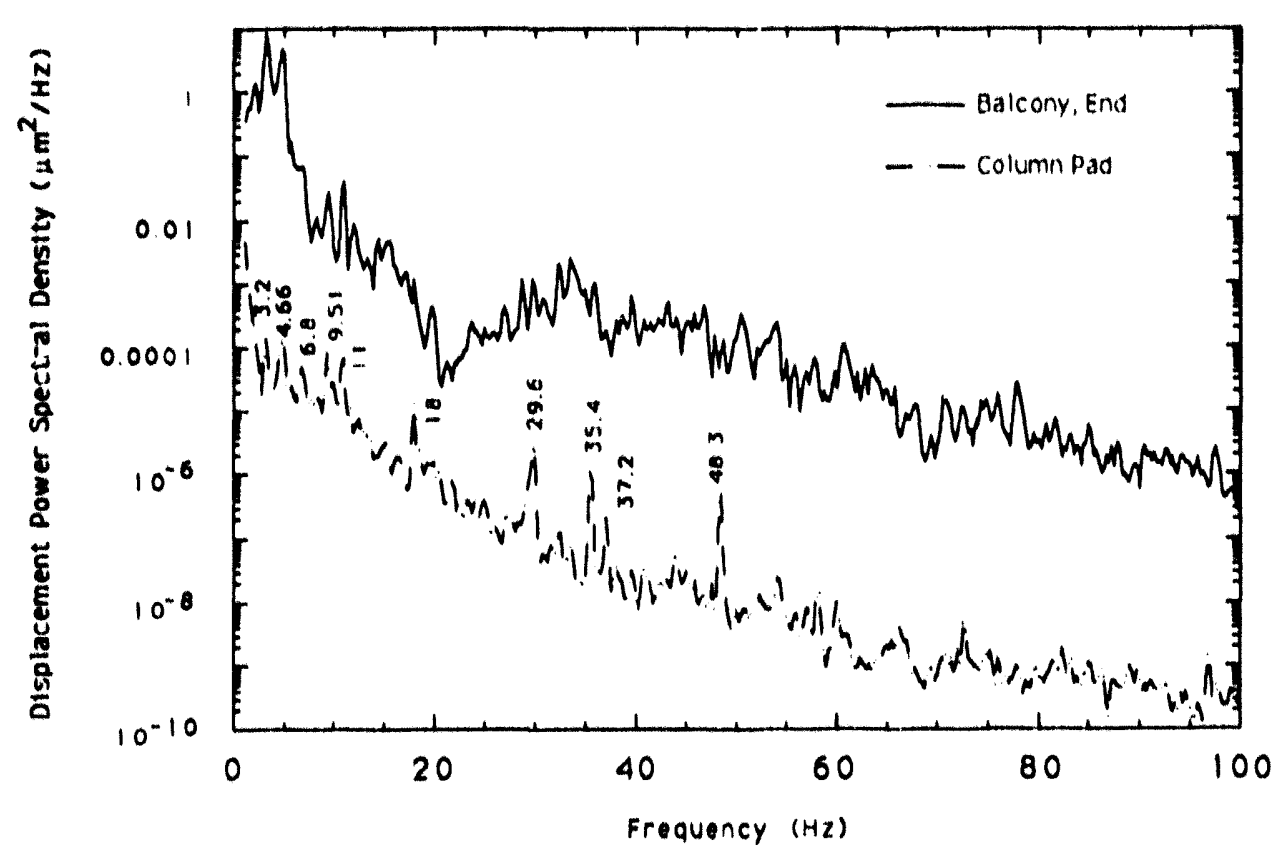

Fig. 21. Spectral density of balcony and column pad displacement with ambient excitation when activity was present on balcony

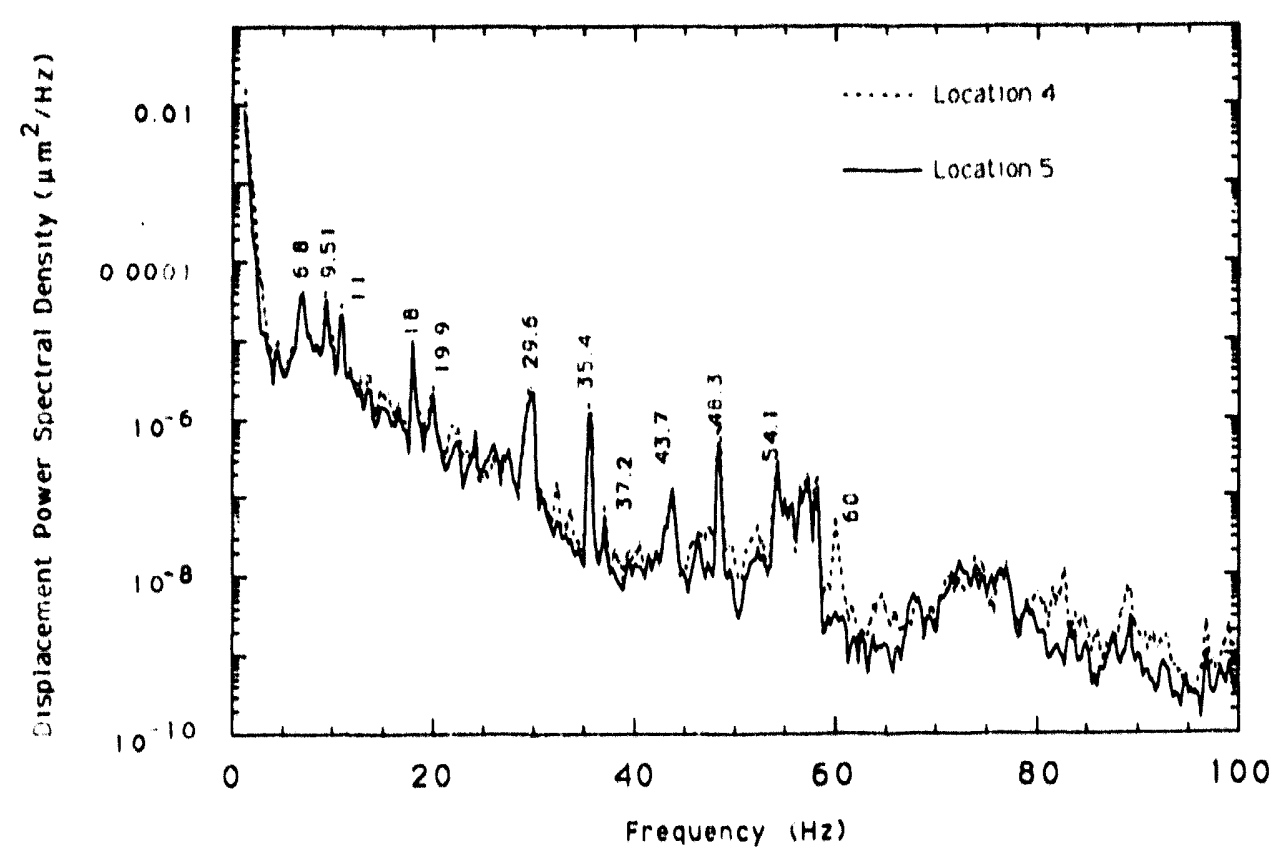

Fig. 22. Spectral density of floor displacement with ambient excitation when activity was present on balcony 


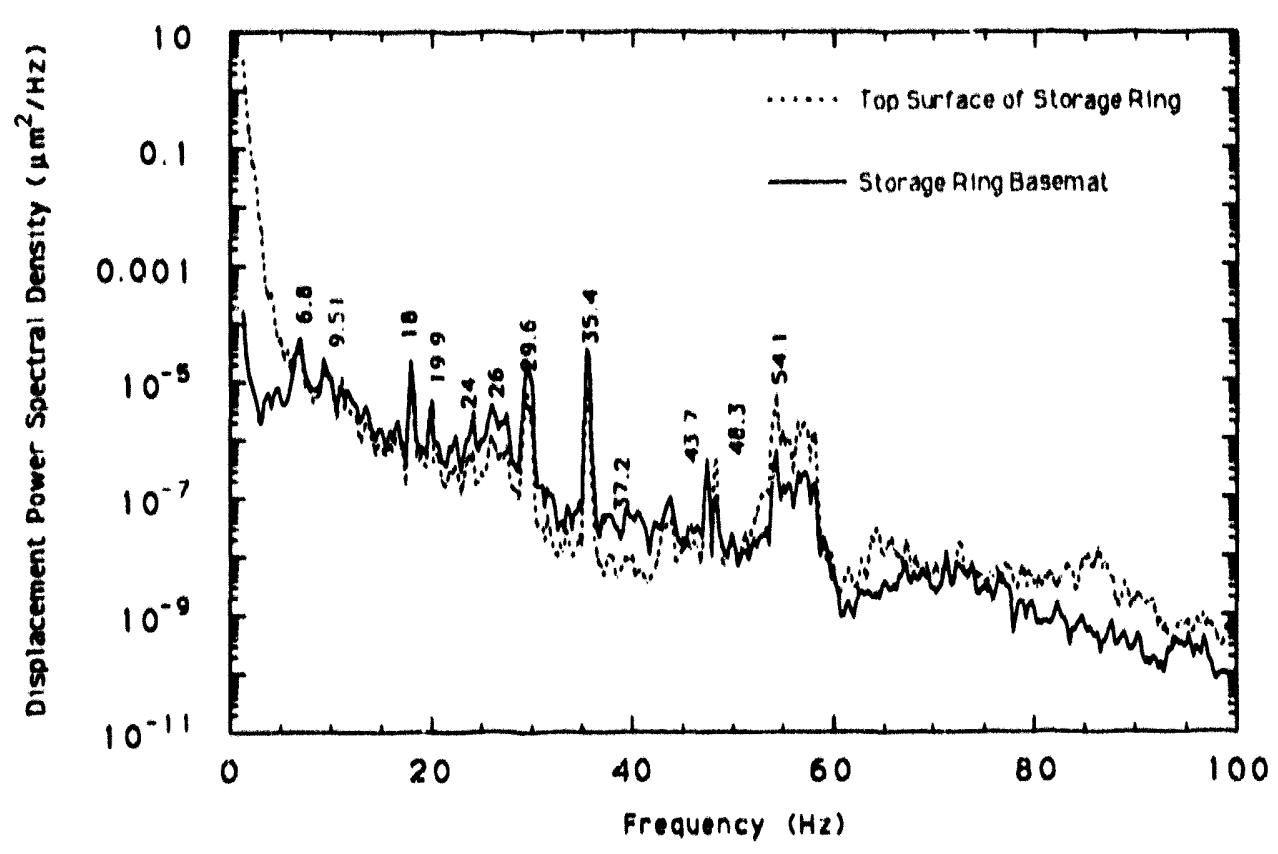

Fig. 23. Spectral density of storage ring displacement with ambient excitation when activity was present on balcony

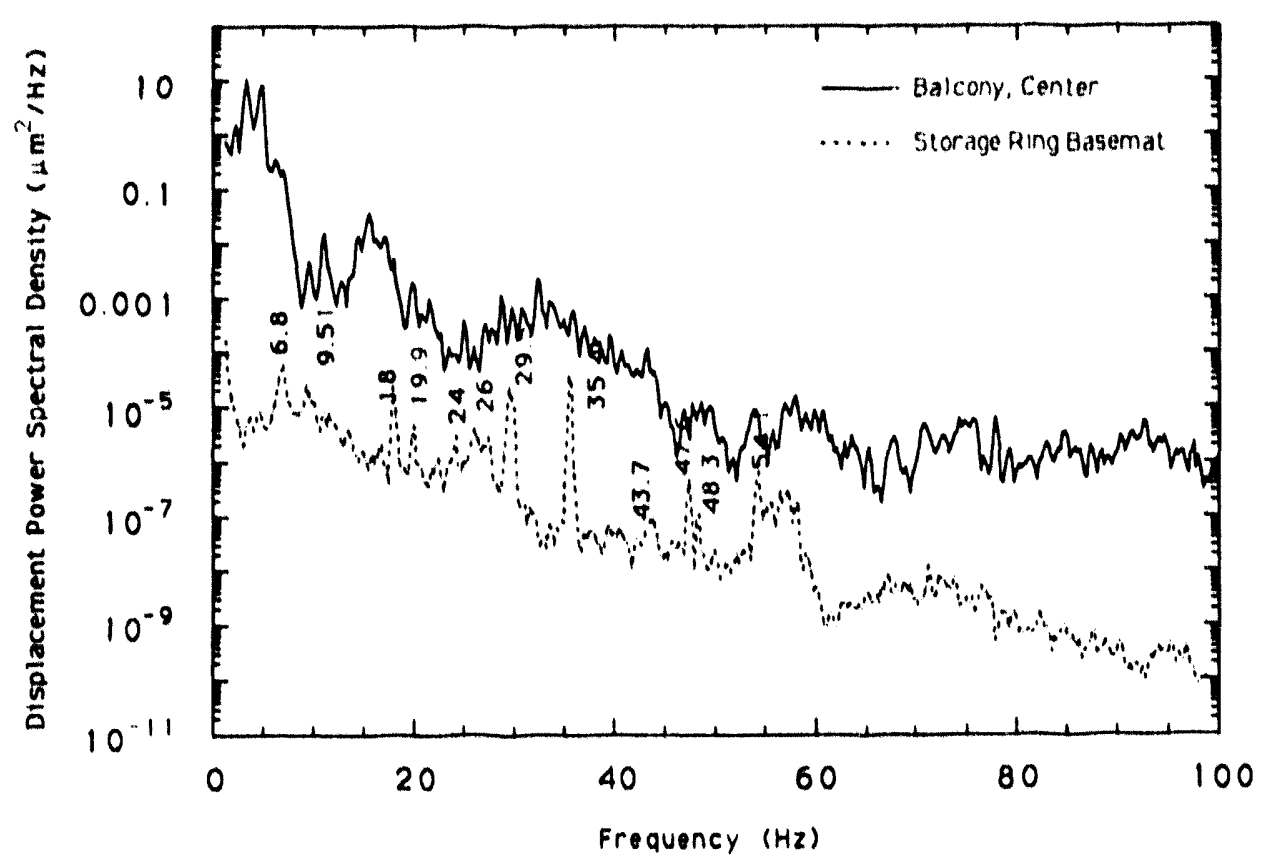

Fig. 24. Spectral density of balcony and storage ring basemat displacement with ambient excitation when activity was present on balcony 


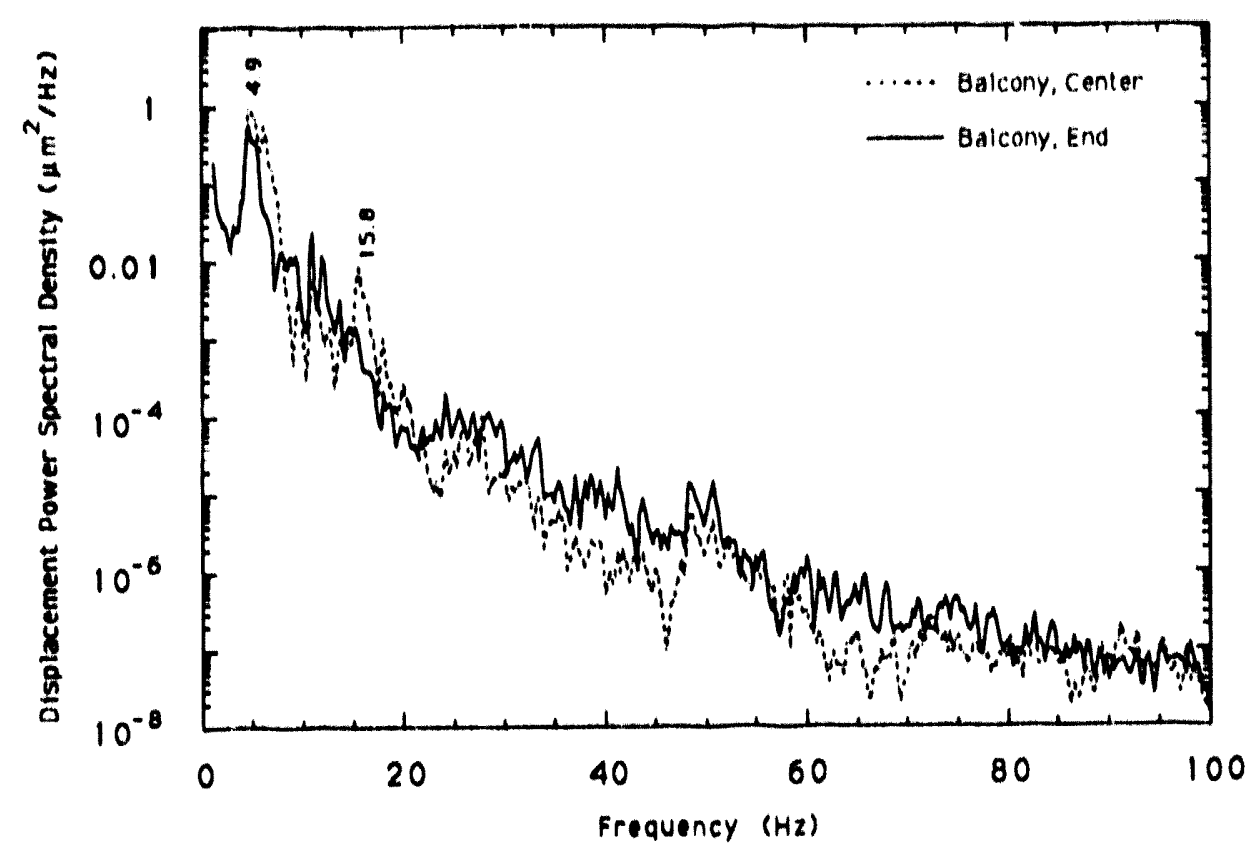

Fig. 25. Spectral density of balcony displacement with ambient excitation when activity was present on balcony

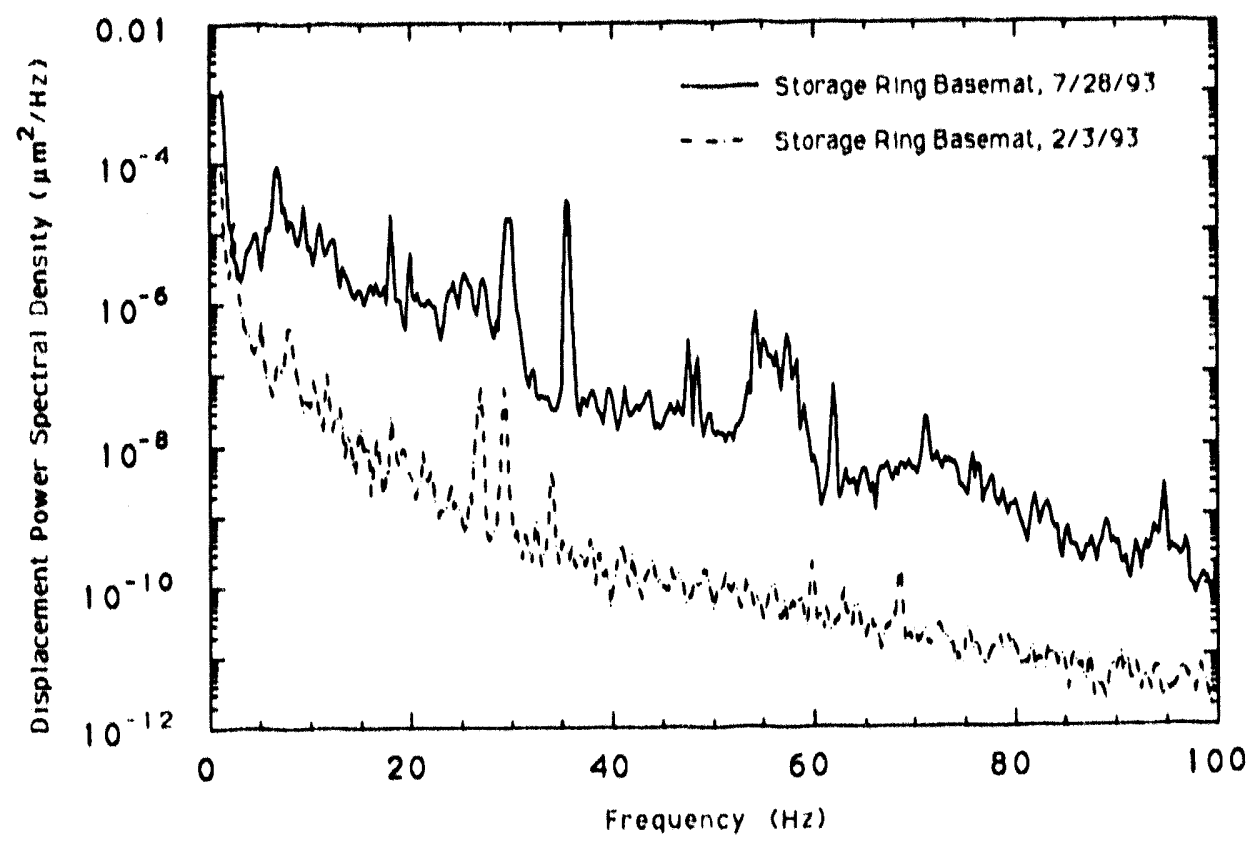

Fig. 26. Spectral density of storage ring basemat on July 28, 1993, and on February 3, 1993 

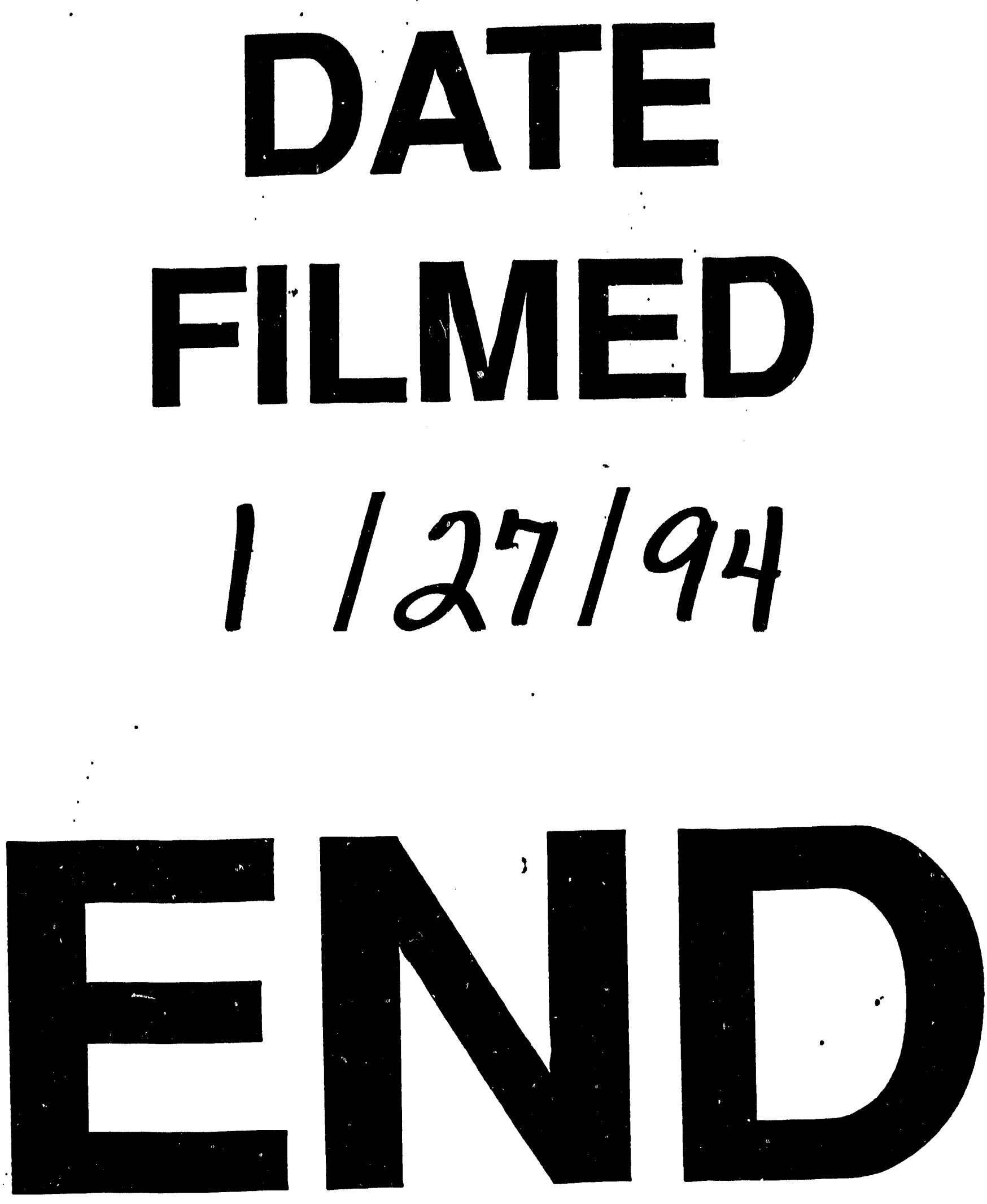
